\title{
Escolas municipais de Campinas e vulnerabilidade sociodemográfica: primeiras aproximações
}

SERGIO STOCO

Universidade Estadual de Campinas

LUANA COSTA ALMEIDA

Universidade Estadual de Campinas

Estudar a disposição espacial da população em relação a determinadas características, seja de vulnerabilidade da região ou mesmo de aspectos ligados à segregação espacial, parece-nos um caminho muito promissor para compreender como algumas especificidades do espaço habitado podem afetar e se manifestar no trabalho da escola com a população atendida por ela.

Nessa perspectiva, o que pretendemos no presente estudo é observar como se manifesta a relação entre as características territoriais do bairro e o desempenho dos estudantes na escola. Para tanto, foram cruzados dados das condições socioespaciais do setor censitário da escola ou suas proximidades (raio de $1 \mathrm{~km}$ do logradouro da escola), com o desempenho escolar de seus alunos, medido a partir do valor agregado. ${ }^{1}$

1 Foram usados dados do Projeto GERES, o qual será apresentado mais adiante. Basicamente o valor agregado medido pelo GERES é o produto da comparação do desempenho dos mesmos alunos (painel de 2005) em exames equalizados e subsequentes a fim de encontrar quanto estes avançaram no período entre as medições. O desenho metodológico da pesquisa preocupou-se em fazer uma medida de entrada de forma que controlasse a proficiência desses alunos ao chegarem nas escolas, possibilitando a comparação dessa medida com as subsequentes, cujo produto é o que foi agregado no período de escolarização considerado, ou seja, o valor agregado pela escola. 
Evidentemente, como já demonstrado pelas pesquisas que tratam de fatores associados ao desempenho escolar, o resultado expresso no desempenho é multidimensional. O que leva a metodologia dessas pesquisas, desde a década de 1950 (Forquin, 1995), a associar o resultado escolar individual ou o resultado médio das classes (turmas) a fatores ligados às características individuais dos estudantes e às condições oferecidas pela escola (professores, gestão, infraestrutura...), conformando um efeito-escola. Ou ainda a fatores vinculados ao espaço habitado pelo estudante, efeito-vizinhança, que também se associa ao ambiente cultural, familiar do estudante, capital cultural.

Dentro desse cenário, um conceito que nos parece essencial para compreendermos a distribuição das escolas no espaço do município e as características das regiões a que pertencem é o de vulnerabilidade social, o qual tem sua origem no conceito de pobreza, amplamente discutido na sociologia dos anos de 1960 e 1970.

A terminologia vulnerabilidade social ganha força $a^{2}$ nas discussões das ciências sociais na década de 1990, principalmente a partir de dois relatórios editados pelo Banco Mundial e coordenados por Caroline Moser. O primeiro (Moser, 1996) resulta de uma pesquisa implementada durante a década de 1980, com o título "Pobreza urbana e política social no contexto de ajuste", realizada na Divisão de Desenvolvimento Urbano do Banco Mundial. O projeto contou com pesquisadores dos quatro países analisados (Zâmbia, Equador, Filipinas e Hungria). O segundo relatório (Moser, 1997) foi preparado como parte do componente de redução da pobreza urbana do Programa de Gestão Urbana, uma iniciativa conjunta da Organização das Nações Unidas para o Desenvolvimento (PNUD), do Programa das Nações Unidas para Assentamentos Humanos (UN-HABITAT) e do Banco Mundial.

Nos estudos apresentados nesses relatórios, Caroline Moser buscou aprimorar as metodologias de observação e captação do fenômeno da pobreza, principalmente destacando sua dinâmica e a capacidade de reação das pessoas a essa condição (Moser, 1998):

O conceito de vulnerabilidade, embora muitas vezes utilizado como sinônimo de pobreza, não é a mesma coisa. Como medidas de pobreza geralmente são fixadas no tempo, a pobreza é essencialmente um conceito estático. Por outro lado, a vulnerabilidade é mais dinâmica e tem melhores condições de capturar a mudança como "as pessoas entram e saem da pobreza" (Lipton;

2 Ganha força em substituição aos conceitos de pobreza ligados a renda e PIB, característicos da década de 1970, ou ainda a noção de necessidades básicas insatisfeitas (NBI) desenvolvida pela Comissão Econômica para a América Latina e o Caribe (CEPAL) na década de 1980. 
Maxwell, 1992, p. 10). Embora as pessoas pobres sejam geralmente as mais vulneráveis, nem todas as pessoas vulneráveis são pobres; esta distinção facilita a diferenciação entre as populações de baixa renda. (p. 3, tradução nossa)

Mesmo antes dessa referência, o conceito de vulnerabilidade nos anos de 1990 expandia-se na área de saúde (particularmente com o avanço dos estudos e diagnósticos sobre a AIDS), depois para a psicologia e assistência social, sempre caracterizando uma forma de distinguir grupos de risco. Nas ciências sociais, particularmente nos estudos desenvolvidos na América Latina, o conceito começa a superar a concepção de posse de ativos materiais como uma responsabilidade do indivíduo e passa a relacionar-se também com os aspectos estruturais da condição social na forma de estrutura de oportunidades.

Por vulnerabilidad social entendemos la incapacidad de una persona o de un hogar para aprovechar las oportunidades, disponibles en distintos ámbitos socioeconómicos, para mejorar su situación de bienestar o impedir su deterioro. [...] las fuentes de vulnerabilidad social más importantes en la actualidad tienen que ver con los fenómenos de precariedad e inestabilidad laboral vinculados al funcionamiento del mercado y con la desprotección e inseguridad ligadas al repliegue del Estado y el debilitamiento de las instituciones primordiales, familia y comunidad. (Kaztman, 2000, p. 281)

Com base nessas afirmações, estar em situação de vulnerabilidade social é mais abrangente que estar em situação de pobreza, pois se refere à condição de não possuir ou não conseguir usar ativos materiais e imateriais que permitiriam ao indivíduo ou grupo social lidar com a situação de pobreza. Dessa forma, os lugares vulneráveis são aqueles nos quais os indivíduos ou grupos sociais enfrentam riscos e a impossibilidade de acesso a serviços e direitos básicos de cidadania, como condições habitacionais, sanitárias, educacionais, de trabalho e de participação e acesso diferencial à informação e às oportunidades oferecidas de forma mais ampla àqueles que possuem essas condições.

Nesse sentido, a questão da vulnerabilidade tem relação direta com a pertença a uma determinada classe social, pois, como evidenciam Hogan e Marandola Jr. (2006, p. 26), estudar as desigualdades sociais e a situação em que vive a população passa pela leitura da sociedade de classes, já que nesta "os diferentes segmentos sociais possuem diferentes oportunidades de vida".

Também para Bilac (2006, p. 52 e 53), “[...] se a 'consciência de classe' tal como expressa nas ações sindicais e nos partidos políticos parece ter arrefecido, a posição de classe continua sendo responsável pelas diferentes condições de vida das famílias em um contexto de enorme desigualdade social”.

Assim, a maior ou menor exposição das famílias ou grupos a riscos sociais depende de sua inserção de classe e das condições de vida dessa classe no contexto 
regional e nacional, já que os riscos e oportunidades não são distribuídos igualmente nos diferentes estratos sociais.

Para Rodríguez (2000), a vulnerabilidade, ao mesmo tempo em que está ligada às vantagens e desvantagens sociais na forma de ativos e oportunidades, é reflexo e produto da pobreza.

Ou, como afirma Kowarick, não é possível dissociar os fenômenos da pobreza e vulnerabilidade do acesso a direitos básicos.

Em suma, há muita vulnerabilidade em relação a direitos básicos, na medida em que não só os sistemas públicos de proteção social foram sempre restritos e precários, como também, em anos recentes, houve desmonte de serviços e novas regulamentações que se traduziram em perda de direitos adquiridos. (Kowarick, 2002, p. 10)

Nessa perspectiva, e até em decorrência da organização da população segundo suas características, oportunidades e possibilidades, podemos associar a esse panorama a questão da segregação espacial.

Geralmente ligado às áreas de geografia, urbanismo e demografia, esse termo carrega um sentido bastante marcado pelas experiências da sociologia urbana da Escola de Chicago no final do século XIX e começo do século XX. Essa referência criou na área das ciências sociais uma tradição de pesquisas que tomam o espaço como resultado de um determinado padrão de organização social. Essa tradição, também conhecida como "ecológica", influenciou diversos estudos que buscavam explicar a paisagem (aspectos físicos do espaço) a partir do comportamento e das características de diferentes grupos sociais.

Esses estudos têm como principal origem e objeto os grandes conglomerados urbanos nos Estados Unidos ${ }^{3}$ e os fenômenos sociais mais pungentes do período, dentre eles a discriminação racial que, certamente, domina o debate da segregação.

A discussão territorial da segunda metade do século XX, já em resposta às pesquisas dessa tradição ecológica, começa a ser influenciada pelo materialismo histórico e pelo marxismo. Essa perspectiva altera a concepção de território apenas como efeito da ação social, trazendo-o à tona também como resultado de um conjunto de forças políticas e econômicas que não apenas o condicionam, mas que também fazem do território um gerador de condições sociais (Santos, 1979).

No desenvolvimento dessas duas perspectivas, habitar determinado espaço pode ser resultado de uma condição econômica (capacidade de mobilidade) determinada pela ação do mercado imobiliário ou da política governamental, ou ainda

3 A cidade de Chicago experimentou um rápido processo de urbanização no final do século XIX e início do XX, transformando-se na capital mundial do automobilismo, o que determinou um padrão produtivo para a indústria mundial. 
uma condição cultural ou social (a permanência, segregação ou migração por raça, etnia, credo, posição política).

Observado por essa perspectiva, o espaço de convivência social pode gerar, entre outras coisas, o fenômeno da segregação, o qual pode ser interpretado como restrição à mobilidade ou ainda como posição homogênea ou não no espaço habitado.

A partir dessa observação, definir a natureza, extensão e efeitos da segregação espacial passa a ser um caminho importante para a interpretação do espaço e dos fenômenos sociais.

Tanto o conceito de vulnerabilidade social quanto o de segregação espacial nos permitem olhar para o espaço de forma mais analítica, percebendo que a localização de determinado segmento da população não se dá de forma aleatória ou inocente, mas influenciada por condições históricas e políticas.

Nesse sentido, é natural que alguns autores tenham procurado relacionar a localização espacial de determinados grupos a fenômenos sociais; estudos dessa natureza recebem o nome de "efeito-vizinhança".

Alves, Franco e Ribeiro (2008) definem o efeito-vizinhança como um conceito que

[...] enquadra-se na categoria geral de modelos explicativos fundados na hipótese da relação de causalidade entre certos acontecimentos e o contexto social no qual ocorrem [...]. Por outras palavras, trata-se de captar o efeito de relações sociais desenvolvidas no âmbito do lugar de moradia sobre desfechos ocorridos na vizinhança. (p. 91)

Os autores indicam ainda que, embora alguns estudos tenham negado a existência do efeito-vizinhança ao tratarem de questões educacionais por acreditarem na maior influência do meio social mais próximo sobre a criança (em especial a família), há estudos desenvolvidos na América Latina que confirmam a hipótese acerca da influência da vizinhança sobre desfechos educacionais.

Pesquisas empíricas como as apresentadas em Ribeiro e Kaztman (2008) apontam a existência de importantes relações entre o universo da vizinhança e o da escola. Também Torres, Ferreira e Gomes (2005) indicam que o elemento espacial tem forte incidência no desempenho escolar dos estudantes.

Entretanto, e por tratar-se da relação com o desempenho escolar, não seria possível passar por essa discussão sem pensarmos em como a instituição (escola) está colocada e/ou se coloca no interior desse fenômeno. Dessa forma, percebemos como promissores os estudos voltados à noção de "efeito-escola", a qual se preocupa em identificar como as escolas podem fazer a diferença para o desempenho dos estudantes.

Essa perspectiva investiga as variáveis intraescolares relacionadas ao bom desempenho escolar das instituições, tendo como metodologia o controle das 
características de ingresso das crianças, para analisar como determinada escola influencia a aprendizagem dos estudantes.

Por efeito-escola entende-se o quanto um dado estabelecimento escolar, pelas suas políticas e práticas internas, acrescenta ao aprendizado do aluno. Essa definição enfatiza a ideia de que cada escola deve ser analisada a partir dos resultados de seu processo de ensino-aprendizagem e que os fatores associados com melhores resultados devem ser identificados. (Brooke; Soares, 2008, p. 10)

Os estudos de efeito-escola surgiram na perspectiva de compreender a influência da escola na aprendizagem das crianças sem limitar sua possibilidade apenas à variável de nível socioeconômico (NSE), em resposta às conclusões oriundas do relatório Coleman ${ }^{4}$ de 1966, que colocavam o NSE como fator determinante do desempenho escolar dos estudantes.

A pesquisa sobre o efeito-escola basicamente passou a defender a necessidade de "abrir a caixa preta" da escola, a fim de entender os processos escolares associados ao desempenho escolar, e também identificar escolas que por suas práticas pedagógicas conseguem levar alunos de origem social e cultural desfavorecida a resultados escolares que contrariam as expectativas. (Bressoux, 2003 apud Alves; Soares, 2007b, p. 27)

Segundo Alves e Soares (2007b), as pesquisas sobre o efeito-escola no Brasil são bem recentes, sendo seus primeiros resultados publicados em meados da década de 1990, com base nos dados acerca da avaliação de sistemas que começaram a ser disponibilizados pelo Instituto Nacional de Pesquisas Educacionais Anísio Teixeira (INEP), órgão do Ministério da Educação. Essas pesquisas "vêm contribuindo para ampliar a compreensão sobre as desigualdades educacionais brasileiras e suas consequências em termos de estratificação social" (Alves; Soares, 2007a, p. 436). Entretanto, autores como Franco (2001) nos alertam para a necessidade de colocarmos atenção nos instrumentos avaliativos utilizados como fonte de dados, já

4 Relatório produzido a partir do extenso survey conduzido por James S. Coleman e seus colaboradores em meados da década de 1960, encomendado por exigência de um dos artigos da Lei de Direitos Civis dos Estados Unidos. Esse relatório concluiu que a diferença entre as escolas seria responsável por pequena fração das diferenças dos desempenhos dos alunos, confirmando estudos anteriores, e indicou que as diferenças socioeconômicas entre os alunos são as responsáveis pelas diferenças em seu desempenho (Brooke; Soares, 2008). 
que aqueles adotados pelas políticas públicas de avaliação em larga escala possuem limitações quanto ao desenho metodológico, o que evidencia a necessidade de escolhas conscientes para uma análise pertinente da problemática.

Em razão disso, os estudos longitudinais seriam os mais adequados, tendo em vista a evidência de que as escolas recebem os alunos com níveis de conhecimento diferenciados e sua aprendizagem varia tanto em função das características dos estudantes, quanto da organização escolar e das práticas pedagógicas das instituições.

Utilizando dados longitudinais e controlando as características iniciais dos alunos, a pesquisa realizada por Rutter, Maughan, Mortimore e Smith em 1979 - excertos disponibilizados em Brooke e Soares (2008) -, indicou que, mesmo em grupos com background semelhante, algumas escolas davam maior chance de bom desempenho escolar que outras, demonstrando que não só esse desempenho estava relacionado às experiências vivenciadas pelos alunos nas escolas, mas também se relacionava às características da própria escola.

Nesse estudo, os autores indicam que fatores como o nível de ajuda proporcionado pelos pais e o envolvimento da comunidade nas escolas certamente vão influenciar como a escola opera como instituição, demonstrando que as variáveis extraescolares também são importantes para a compreensão do desempenho dessas instituições e, assim, da análise de sua qualidade.

Porém, como nos alertam Soares e Andrade, "nem os fatores extraescolares conseguem sozinhos explicar o desempenho cognitivo, nem a escola faz toda a diferença" (2006, p. 109), manifestando-se a necessidade de entendermos de forma mais ampla e abrangente como esses fatores influenciam o desempenho nas escolas.

Nessa perspectiva, a possibilidade de análise da escola a partir da noção de espaço habitado emerge como promissora para a compreensão das variáveis extraescolares de forma que evidencie o contexto social em que se circunscreve o fenômeno.

A problemática apontada aqui nos mobiliza a estudar as Escolas Municipais de Campinas, examinando a relação entre seu desempenho escolar e sua localização territorial nas zonas de vulnerabilidade social da cidade.

\section{CARACTERIZAÇÃO DO ENTORNO DAS ESCOLAS}

Os dados analisados neste estudo têm como fontes principais dois projetos desenvolvidos respectivamente pelo grupo de pesquisa do Laboratório de Observação e Estudos Descritivos (LOED) (FE - UNICAMP), acerca do desempenho escolar nas escolas das diferentes redes de ensino de Campinas, e pelo grupo de pesquisa Núcleo de Estudos de População (NEPO) (UNICAMP), acerca da vulnerabilidade social na região metropolitana de Campinas. 
O projeto "Estudo longitudinal sobre qualidade e eficácia no ensino fundamental brasileiro: GERES 2005” diferencia-se dos demais sistemas de avaliação em larga escala de estudantes em curso no Brasil por seu desenho metodológico longitudinal (painel), que permitiu a observação de uma mesma amostra de alunos ao longo dos anos iniciais do ensino fundamental, dando um panorama acerca do que aprende nos diferentes anos um mesmo grupo de alunos (Coorte, 2005).

A pesquisa abrangeu mais de 20 mil crianças, em mais de trezentas escolas, nas cinco cidades participantes do estudo, a partir da medição do desempenho em leitura e matemática, obtendo-se um retrato da evolução da aprendizagem da geração escolar que começou seus estudos em 2005.

Os principais objetivos do projeto foram identificar as características escolares que maximizam a aprendizagem dos alunos e que minimizam o impacto da origem social sobre o aprendizado; identificar os fatores escolares que diminuem a probabilidade de repetência dos alunos e identificar aquelas características da escola que reduzem a probabilidade da repetência e evasão escolar (Franco; Brooke; Alves, 2008).

O projeto "Dinâmica intrametropolitana e vulnerabilidade sociodemográfica

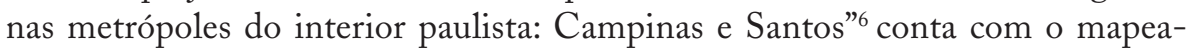
mento das zonas de vulnerabilidade das regiões pesquisadas (construídas a partir dos dados provindos do Censo 2000) e com o levantamento de informações ao longo do segundo semestre de 2007, a partir de uma pesquisa domiciliar realizada em 1680 domicílios escolhidos por meio de uma amostra aleatória especialmente desenhada para refletir a heterogeneidade espacial da região em termos do grau de vulnerabilidade das famílias.

A definição do que se chamou no projeto de "zonas de vulnerabilidade" partiu da concepção teórica de que a situação de vulnerabilidade decorreria da exposição a determinados riscos, e particularmente os riscos ligados à pobreza, expressando-se na ausência (ou escassez) de certos tipos de ativos que poderiam ser classificados em termos de três categorias de capitais: físico/financeiro, humano e social ${ }^{7}$, organizadas em fatores de variáveis disponíveis do Censo 2000.

5 O projeto foi desenvolvido por pesquisadores de diferentes instituições, dentre elas: UFMG, PUC-Rio, UEMS, UFBa, UNICAMP e UFJF; e teve a participação de cinco cidades: Belo Horizonte, Rio de Janeiro, Campo Grande, Salvador e Campinas.

6 O projeto foi desenvolvido por pesquisadores do NEPO e colaboradores, com financiamento da FAPESP e CNPq, no período de 2004 a 2008.

7 Definições retiradas do Sumário de Dados da Região Metropolitana de Campinas. Disponível em: <http://www.nepo.unicamp.br/vulnerabilidade/sumario/sumario_final_RMC/index.html>. Para maiores detalhes sobre esse procedimento, ver Cunha et al. (2006a). 


\section{Quadro 1 - Variáveis do Censo 2000 utilizadas para montagem das zonas de vulnerabilidade}

\begin{tabular}{|c|c|c|c|c|c|c|c|}
\hline \multicolumn{3}{|c|}{ Capital físico } & \multicolumn{2}{|c|}{ Capital humano } & \multicolumn{3}{|c|}{ Capital social } \\
\hline \multirow{2}{*}{ Variáveis } & \multicolumn{2}{|c|}{ Fatores } & \multirow{2}{*}{ Variáveis } & \multirow{2}{*}{$\begin{array}{c}\text { Fator } \\
1 \\
\end{array}$} & \multirow{2}{*}{ Variáveis } & \multicolumn{2}{|c|}{ Fatores } \\
\hline & 1 & 2 & & & & 1 & 2 \\
\hline $\begin{array}{l}\text { densmor } \\
\text { comodo }\end{array}$ & 0.871 & 0.372 & pessanalf $15+$ & 0.968 & $\begin{array}{l}\text { chefe } \\
\text { fam10a19 }\end{array}$ & 0.674 & 0.034 \\
\hline $\begin{array}{l}\text { renchefe } \\
\text { fam0a2 }\end{array}$ & 0.777 & 0.507 & $\begin{array}{l}\text { escchefe } \\
\text { fam0a4 }\end{array}$ & 0.964 & tamfamília & 0.429 & -0.692 \\
\hline tipocasa & 0.851 & -0.052 & $\begin{array}{l}\text { razão } \\
\text { dependência }\end{array}$ & 0.914 & $\begin{array}{l}\text { outros } \\
\text { agregados }\end{array}$ & 0.241 & 0.819 \\
\hline $\begin{array}{l}\text { tipo } \\
\text { comodo }\end{array}$ & 0.237 & 0.722 & & & $\begin{array}{l}\text { s/carteira } \\
\text { assinada }\end{array}$ & 0.706 & -0.319 \\
\hline $\begin{array}{l}\text { cond.prop. } \\
\text { aquis. }\end{array}$ & 0.175 & -0.031 & & & $\begin{array}{l}\text { nãofreq } \\
\text { escola7a14 }\end{array}$ & 0.804 & 0.054 \\
\hline cond.alugado & -0.752 & -0.214 & & & $\begin{array}{l}\text { famrenda } \\
\text { nãotrabalho }\end{array}$ & -0.670 & 0.576 \\
\hline $\begin{array}{l}\text { água não } \\
\text { canaliz }\end{array}$ & 0.069 & 0.740 & & & & & \\
\hline 2+banheiros & -0.779 & -0.279 & & & & & \\
\hline s/redeesgoto & 0.391 & 0.547 & & & & & \\
\hline s/coleta lixo & 0.225 & 0.594 & & & & & \\
\hline $\begin{array}{l}\text { \% var. } \\
\text { explicada }\end{array}$ & 35.53 & 22.45 & $\begin{array}{l}\text { \% var. } \\
\text { explicada }\end{array}$ & 90.09 & $\begin{array}{l}\text { \% var. } \\
\text { explicada }\end{array}$ & 38.17 & 26.46 \\
\hline $\begin{array}{c}\text { Interpretação } \\
\text { sugerida dos } \\
\text { fatores }\end{array}$ & $\begin{array}{l}\text { Padrão de } \\
\text { ocupação } \\
\text { periférico }\end{array}$ & $\begin{array}{c}\text { Deficiência } \\
\text { na infra- } \\
\text {-estrutura } \\
\text { domiciliar }\end{array}$ & & $\begin{array}{c}\text { Carência de } \\
\text { capital } \\
\text { humano }\end{array}$ & & $\begin{array}{l}\text { Desproteção } \\
\text { social }\end{array}$ & $\begin{array}{c}\text { Estratégia } \\
\text { familiar de } \\
\text { proteção } \\
\text { social }\end{array}$ \\
\hline
\end{tabular}

Fonte: Extraído de Cunha (2006).

Tendo em vista os resultados acerca da vulnerabilidade obtidos na pesquisa, convencionou-se a seguinte classificação analítica das zonas de vulnerabilidade:

1|Vulnerabilidade absoluta: para as áreas onde em praticamente todas as dimensões eram desfavoráveis.

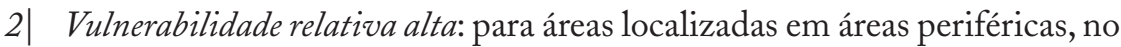
entanto, mais consolidadas em termos da infraestrutura urbana, que, na verdade, é o que as diferenciam essencialmente da situação anterior.

$3 \mid$ Vulnerabilidade relativa média: áreas com condição socioeconômica sensivelmente melhor que as anteriores, mas ainda com deficiência tanto no capital físico como humano.

4 Vulnerabilidade relativa baixa: áreas mais centrais da cidade, com mais alta renda e com composições familiares com maior predominância de pessoas sós, idosos etc. 


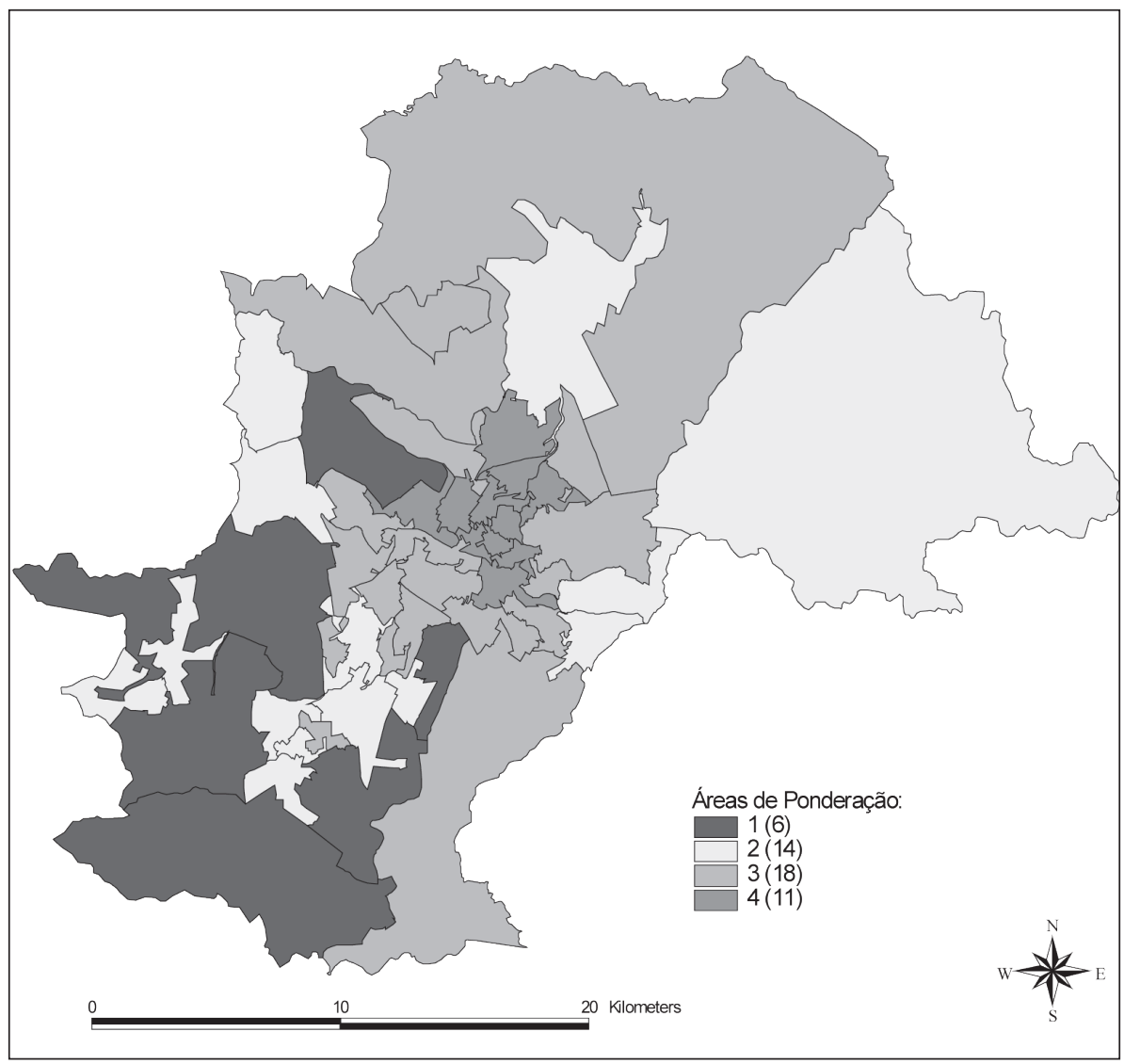

Figura 1: Mapa do município de Campinas com indicação das zonas de vulnerabilidade. Fonte: Extraído de Cunha (2006).

Para escolher as unidades escolares que fariam parte do nosso trabalho de análise, selecionamos as escolas municipais de Campinas acompanhadas pelo Projeto GERES, que se localizam nas regiões (setores censitários) e que também tinham informações amostradas pela pesquisa domiciliar do projeto do NEPO. A partir disso, realizamos um estudo cartográfico dos logradouros dessas escolas, o que possibilitou cruzar informações (variáveis) disponíveis para aquela escola e seu entorno nas duas pesquisas utilizadas como fonte.

A partir do cruzamento dos dados das escolas provenientes dos bancos do GERES e do NEPO, pudemos localizar 14 escolas GERES no mapa de vulnerabilidade. As escolas da rede municipal constituintes da amostra do Projeto GERES foram 21, entretanto sete estão localizadas em áreas não abrangidas pelo critério de distância do raio de $1 \mathrm{~km}$ do logradouro da escola, considerados os setores censitários sorteados para a amostra do Projeto do NEPO. Isso demonstrou uma 
distribuição heterogênea e periférica ${ }^{8}$ no espaço, o que faz com que tenhamos em nossa amostragem escolas das quatro zonas de vulnerabilidade mapeadas no estudo.

Quadro 2 - Distribuição das escolas por zona de vulnerabilidade

\begin{tabular}{|c|c|}
\hline Zonas de Vulnerabilidade & Escolas \\
\hline ZV 1 & $\mathrm{K}, \mathrm{M}, \mathrm{N}$ \\
\hline Fronteira entre 1 e 2 & $\mathrm{G}, \mathrm{H}$ \\
\hline ZV 2 & B, I, J \\
\hline Fronteira entre 2 e 3 & A, L \\
\hline ZV 3 & C, D, F \\
\hline ZV 4 & E \\
\hline
\end{tabular}

Fonte: Dados elaborados a partir das pesquisas GERES 2005 e vulnerabilidade.

Diversos estudos, como Andrade et al. (2008); Bichir, Torres e Ferreira (2005); Ribeiro e Kaztman (2008) e Cunha et al. (2006b), têm demonstrado a relação das condições socioeconômicas do lugar (bairro ou região) e suas causas ou efeitos nas condições de vida da população (renda, trabalho, escola, saúde etc.). Muitos desses têm também associado à condição do lugar a segregação socioespacial (Marques; Torres, 2005; Cunha et al., 2006a). Dessa forma, para a compreensão mais detalhada do entorno da escola, optamos por localizá-las em seus respectivos setores censitários ${ }^{9}$. Essa opção justifica-se pela possibilidade, a partir da pesquisa do NEPO sobre vulnerabilidade, de termos acesso a uma caracterização diferenciada de variáveis levantadas na pesquisa domiciliar, ${ }^{10}$ sendo possível, para além de dados acerca de sua localização espacial, compreender como as pessoas vivem nessas regiões.

Nesse sentido, a opção pela delimitação nos setores censitários nos permitirá observar, além da distribuição de serviços e infraestrutura, a percepção dos residentes do local acerca da vida cotidiana nessas regiões (violência e permanência no bairro).

Foram escolhidos setores censitários do logradouro das escolas selecionadas e outros setores censitários que estivessem no entorno da escola com critério de escolha de distanciamento máximo de $1 \mathrm{~km}$. O parâmetro escolhido justifica-se

8 A Rede Municipal de Campinas conta com mais escolas concentradas nas regiões periféricas da cidade, já que a área mais central (área de ocupação mais antiga da cidade, representada na zona de vulnerabilidade 4 no mapa) conta com os seculares colégios estaduais do início do século XX e caracteriza-se por ser uma região de menor crescimento populacional e de distribuição etária envelhecida.

9 Estamos denominando fronteira as escolas que possuem no seu entorno setores censitários de duas zonas de vulnerabilidade diferentes, devido ao fato de pertencerem a diferentes áreas de ponderação.

10 Considerando os entrevistados residentes nos setores censitários selecionados para este trabalho, temos 341 domicílios e 1.139 pessoas. 
pelo fato de que o sistema de matrículas na Rede Municipal de Campinas utiliza o georreferenciamento como critério para efetivá-las; além disso, entre os respondentes da pesquisa nos setores censitários do entorno das escolas, 90\% informaram que existe uma escola pública a menos de 30 minutos a pé de suas residências (sendo que $61 \%$ levam de 6 a 10 minutos a pé para chegar à escola) e 55,6\% dos que estudam vão a pé para a escola.

Essa caracterização permite uma visão parcial do contexto no qual as escolas estão inseridas. Uma caracterização mais pormenorizada exigiria um estudo de caso dos bairros (estimando melhor o efeito-vizinhança, a vulnerabilidade e o processo de segregação espacial). Mas, certamente, a versão apresentada nos limites deste estudo é uma abordagem inicial dessa análise pormenorizada que já está prevista em novo projeto (FAPESP) em fase de delimitação.

A descrição da infraestrutura urbana, escolaridade e classe de consumo da população, percepção da violência, da disponibilidade de serviços e de acesso à cultura e lazer permitem caminhar para uma metodologia que utiliza como variável descritiva do lugar uma concepção mais ampla do que a consideração do nível socioeconômico a partir da renda e propriedade, como, por exemplo, em Soares, Rigotti e Andrade (2008), aproximando-se de uma caracterização mais aberta sem a necessidade de escalonar a contribuição de cada variável por meio de fatoração, como realizado em Solis (2008). Dessa forma, introduzimos no banco de dados como "variável link" as escolas relacionadas aos setores censitários adjacentes, fizemos uma leitura e análise de todas as frequências das variáveis disponíveis (inclusive alguns cruzamentos) para cada escola na pesquisa domiciliar realizada em 2007 e procedemos à caracterização do entorno das escolas de nossa amostra:

\section{Condições da rua}

Nos setores censitários compreendidos pelas escolas em áreas de maior vulnerabilidade (em geral áreas de ocupação mais recente do município), as escolas $\mathrm{G}$ e $\mathrm{H}$ possuem, respectivamente, $25 \%$ e $20 \%$ das ruas de terra com cascalho; além disso, na região da escola G, 45\%, e na da escola N, 100\% das ruas são de terra irregular. As áreas das outras 11 escolas são pavimentadas e em boas condições, chamando a atenção apenas as ruas do entorno da escola $\mathrm{F}$, onde $41 \%$ dos respondentes afirmaram se tratar de ruas pavimentadas com buracos. Em relação à iluminação pública, apenas no entorno da escola $\mathrm{H}, 10 \%$ dos respondentes afirmaram não ter iluminação (em todos os outros setores os números estão próximos ou tem exatamente 100\% de respostas positivas).

\section{Casa}

A maioria dos entrevistados na pesquisa do NEPO reside em casas térreas, entretanto, quando observamos a distribuição dos respondentes por setores censitários, chama a atenção o entorno da escola I, que tem 100\% dos respondentes 
morando em apartamentos de um conjunto habitacional popular. Com exceção de áreas de maior vulnerabilidade (entorno das escolas $\mathrm{G}, \mathrm{J}$ e N, com aproximadamente $25 \%$ de respostas de parede interna da casa sem revestimento), todas as outras áreas têm próximo de $100 \%$ das casas com revestimento interno nas paredes. Nas regiões das escolas $\mathrm{G}$ e $\mathrm{N}$, aproximadamente $90 \%$ das residências não são regularizadas ou estão em processo de regularização. Destaca-se também o fato de que $23 \%$ dos respondentes das áreas das escolas $\mathrm{M}$ e $\mathrm{N}$, e $17 \%$ da área da escola $\mathrm{C}$, residirem em outras cidades e municípios cinco anos antes da entrevista, sendo que $54 \%$ de todos os entrevistados considerados nesta pesquisa já mudaram de residência duas ou mais vezes dentro do município.

\section{Alagamento}

Existe um número significativo de setores nos quais moradores residem a menos de cinco quarteirões de rios, córregos, lagoas, represas ou mangues, o que aumenta o risco de alagamentos e enchentes. Nas regiões das escolas B e G, 100\% dos respondentes estão nessa condição; em J e K, mais de 80\%, e em C, F, H, I e $\mathrm{N}$, entre $50 \%$ e $80 \%$.

Água, resíduos e esgoto

A maioria dos setores recebe água continuamente, mas os setores censitários relacionados às escolas $\mathrm{A}, \mathrm{B}, \mathrm{D}, \mathrm{G}, \mathrm{H}, \mathrm{I}, \mathrm{K}, \mathrm{L}, \mathrm{M}$ e $\mathrm{N}$ não possuem coleta diária do lixo.

Nas regiões G (42\%), K (61\%) e N (93\%), o escoamento de esgoto é feito por ligação a fossas sépticas, fato que, associado com as respostas sobre a proximidade da residência a rios, córregos e mangues, gera risco iminente à saúde pública.

\section{Escolaridade e classe de consumo}

A distribuição da escolaridade e da classe de consumo (critério ABIPEME) segue a relação proporcional da localização dos setores nas diferentes zonas de vulnerabilidade (quanto mais vulnerável menor a escolaridade e a classificação na classe de consumo), como demonstram as Tabelas 1 e 2.

Podemos encontrar, por exemplo, o entorno da região da escola M com 51,1\% dos respondentes nos domicílios classificados como analfabetos ou com primeiro ciclo (até quarta série) incompletos, atingindo no máximo o ensino fundamental completo ou médio incompleto, $12,1 \%$. 
Tabela 1 - Escolaridade por setor censitário de cada uma das escolas GERES

\begin{tabular}{|c|c|c|c|c|c|}
\hline \multicolumn{6}{|c|}{ Escolaridade } \\
\hline Escola & $\begin{array}{c}\text { Analfabetol } \\
\text { Fundamental } 1^{0} \\
\text { ciclo incompleto } \\
\text { (1 } 1^{\mathrm{a}} \text { a } 4^{\mathrm{a}} \text { séries) }\end{array}$ & $\begin{array}{c}\text { Fundamental } \\
2^{0} \text { ciclo } \\
\text { incompleto } \\
\text { (5 } 5^{\mathrm{a}} \text { a } 8^{\mathrm{a}} \text { séries) }\end{array}$ & $\begin{array}{l}\text { Fundamental } \\
\text { completo/ } \\
\text { Médio } \\
\text { incompleto }\end{array}$ & $\begin{array}{c}\text { Médio } \\
\text { completo/ } \\
\text { Superior } \\
\text { incompleto }\end{array}$ & $\begin{array}{l}\text { Superior } \\
\text { completo/ } \\
\text { Pós- } \\
\text {-Graduação }\end{array}$ \\
\hline B & $26 \%$ & $34 \%$ & $12,0 \%$ & $28,0 \%$ & $0 \%$ \\
\hline $\mathrm{C}$ & $22 \%$ & $29,9 \%$ & $21,3 \%$ & $16,5 \%$ & $10,2 \%$ \\
\hline D & $0 \%$ & $7,8 \%$ & $11,8 \%$ & $25,5 \%$ & $54,9 \%$ \\
\hline E & $11,4 \%$ & $21 \%$ & $13,3 \%$ & $38,1 \%$ & $16,2 \%$ \\
\hline $\mathbf{F}$ & $16 \%$ & $30,4 \%$ & $11,2 \%$ & $40 \%$ & $2,4 \%$ \\
\hline G & $20,6 \%$ & $42,6 \%$ & $13,2 \%$ & $23,5 \%$ & $0 \%$ \\
\hline $\mathbf{H}$ & $19,0 \%$ & $21,2 \%$ & $25,5 \%$ & $29,2 \%$ & $5,1 \%$ \\
\hline I & $0 \%$ & $5,6 \%$ & $19,4 \%$ & $61,1 \%$ & $13,9 \%$ \\
\hline $\mathbf{J}$ & $7,1 \%$ & $39,3 \%$ & $32,1 \%$ & $21,4 \%$ & $0 \%$ \\
\hline $\mathbf{K}$ & $8,2 \%$ & $49,2 \%$ & $42,6 \%$ & , 0\% & $0 \%$ \\
\hline $\mathrm{A} / \mathrm{L}$ & $28,0 \%$ & $30,3 \%$ & $13,7 \%$ & $28,0 \%$ & $0 \%$ \\
\hline M & $51,5 \%$ & $12,1 \%$ & $0 \%$ & $36,4 \%$ & $0 \%$ \\
\hline $\mathrm{N}$ & $31,9 \%$ & $46,8 \%$ & $14,9 \%$ & $6,4 \%$ & $0 \%$ \\
\hline
\end{tabular}

Fonte: Dados elaborados a partir das pesquisas GERES 2005 e vulnerabilidade.

Tabela 2 - Classe de consumo por setor censitário de cada uma das escolas GERES

\begin{tabular}{c|c|c|c|c|c|c|c}
\hline \multicolumn{7}{c}{ CLASSE de CONSUMO padrão ABIPEME } \\
\hline Escola & Classe E & Classe D & Classe C & Classe B2 & Classe B1 & Classe A2 & Classe A1 \\
\hline B & $0 \%$ & $30,8 \%$ & $30,8 \%$ & $38,5 \%$ & $0 \%$ & $0 \%$ & $0 \%$ \\
C & $0 \%$ & $26,3 \%$ & $55,3 \%$ & $10,5 \%$ & $7,9 \%$ & $0 \%$ & $0 \%$ \\
D & $0 \%$ & $0 \%$ & $41,2 \%$ & $17,6 \%$ & $17,6 \%$ & $17,6 \%$ & $5,9 \%$ \\
E & $0 \%$ & $3,1 \%$ & $50 \%$ & $21,9 \%$ & $21,9 \%$ & $0 \%$ & $3,1 \%$ \\
F & $0 \%$ & $8,3 \%$ & $41,7 \%$ & $27,8 \%$ & $16,7 \%$ & $5,6 \%$ & $0 \%$ \\
G & $0 \%$ & $25 \%$ & $72,5 \%$ & $2,5 \%$ & $0 \%$ & $0 \%$ & $0 \%$ \\
H & $6,1 \%$ & $30,6 \%$ & $36,7 \%$ & $22,4 \%$ & $4,1 \%$ & $0 \%$ & $0 \%$ \\
I & $0 \%$ & $12,5 \%$ & $62,5 \%$ & $25 \%$ & $0 \%$ & $0 \%$ & $0 \%$ \\
J & $6,7 \%$ & $20 \%$ & $53,3 \%$ & $20 \%$ & $0 \%$ & $0 \%$ & $0 \%$ \\
K & $0 \%$ & $33,3 \%$ & $61,1 \%$ & $0 \%$ & $5,6 \%$ & $0 \%$ & $0 \%$ \\
A/L & $0 \%$ & $41,9 \%$ & $46,5 \%$ & $9,3 \%$ & $2,3 \%$ & $0 \%$ & $0 \%$ \\
M & $10 \%$ & $30 \%$ & $50 \%$ & $10 \%$ & $0 \%$ & $0 \%$ & $0 \%$ \\
N & $0 \%$ & $42,9 \%$ & $57,1 \%$ & $0 \%$ & $0 \%$ & $0 \%$ & $0 \%$ \\
\hline
\end{tabular}

Fonte: Dados elaborados a partir das pesquisas GERES 2005 e vulnerabilidade. 
Serviços no entorno

$\mathrm{Na}$ distribuição por setores, o atendimento do serviço público tende a concentrar-se nas áreas mais populosas e carentes.

Essa tendência não se confirma, no entanto, nos setores de entorno das escolas B, H, I e J, com distribuição entre 60\% e 90\% de moradores que levam, a pé, mais de dez minutos para chegar a um posto de saúde. $\mathrm{O}$ que, em relação ao serviço de creche, acontece com mais de $60 \%$ para os moradores do entorno das escolas $\mathrm{G}$, I e J. E, perguntados sobre a dificuldade de conseguir atendimento do serviço de saúde do posto, na região das escolas B, K e M, aproximadamente 60\% dos respondentes afirmaram ter alguma ou muita dificuldade de obter o serviço.

A proximidade da escola pública e a grande distância do posto policial são características de todas as regiões da cidade.

Perguntados sobre a dificuldade de conseguir atendimento do serviço policial, as regiões que apresentam alguma dificuldade ou muita dificuldade, em proporção significativa, são o entorno das escolas F, G, J e N, com aproximadamente 70\% dos respondentes nessa opção.

Quanto a serviços comerciais, mais de $60 \%$ da população residente nas áreas $\mathrm{G}, \mathrm{J}$ e K tem acesso à farmácia com mais de 10 minutos de distância a pé em relação a sua residência. Quando perguntados sobre acreditar ser uma vantagem morar no bairro, as regiões das escolas B, $\mathrm{H} \mathrm{e} \mathrm{J} \mathrm{tiveram} \mathrm{índice} \mathrm{de} \mathrm{resposta} \mathrm{negativo} \mathrm{entre} 30 \%$ e 40\%. Quanto às respostas que indicam satisfação por morar no bairro nas áreas classificadas como de baixa vulnerabilidade destaca-se a facilidade da proximidade dos serviços já mencionados, enquanto nas áreas de alta vulnerabilidade as principais características são a proximidade de parentes e o preço dos terrenos/casas.

Destacamos, todavia, que na maioria das áreas de alta vulnerabilidade há um equilíbrio entre as respostas sobre parentes e preços de corretagem, tendendo a ser maior para parentes, exceção feita a área $\mathrm{G}$, que tem $56 \%$ dos respondentes concentrados na resposta da vantagem apontada ser o preço de aluguéis e terrenos.

\section{Violência}

Quase todos os setores da cidade indicam a violência como um perigo do bairro, mas a distribuição dessa percepção não está associada diretamente à zona de vulnerabilidade de pertencimento (nas áreas das escolas B, H, K e M, a maioria não identificou a violência como perigo). 
Tabela 3 - Percepção da violência por setor censitário das escolas GERES

\begin{tabular}{|c|c|c|}
\hline \multicolumn{3}{|c|}{ Percepção de perigo no bairro } \\
\hline \multirow{2}{*}{ Área da escola } & \multicolumn{2}{|c|}{$\begin{array}{l}\text { Questão - } 0 \text { sr. acha que a violência é um perigo } \\
\text { aqui no seu bairro? }\end{array}$} \\
\hline & Sim & Não há perigo \\
\hline B & $23,1 \%$ & $76,9 \%$ \\
\hline $\mathrm{C}$ & $84,2 \%$ & $15,8 \%$ \\
\hline D & $70,6 \%$ & $29,4 \%$ \\
\hline $\mathbf{E}$ & $81,3 \%$ & $18,8 \%$ \\
\hline $\mathbf{F}$ & $72,2 \%$ & $27,8 \%$ \\
\hline G & $95 \%$ & $5 \%$ \\
\hline $\mathbf{H}$ & $38,8 \%$ & $61,2 \%$ \\
\hline I & $81,3 \%$ & $18,8 \%$ \\
\hline $\mathbf{J}$ & $66,7 \%$ & $33,3 \%$ \\
\hline $\mathbf{K}$ & $27,8 \%$ & $72,2 \%$ \\
\hline$A / L$ & $74,4 \%$ & $25,6 \%$ \\
\hline M & $10 \%$ & $90 \%$ \\
\hline $\mathbf{N}$ & $100 \%$ & $0 \%$ \\
\hline
\end{tabular}

Fonte: Dados elaborados a partir das pesquisas GERES 2005 e vulnerabilidade.

Porém, quando essa violência é caracterizada por tipos de crime, há algumas regiões que apontam o tráfico de drogas como a principal preocupação; são elas: B (66\%), G (73\%), I (76\%) e N (78\%), sendo que na região K, 20\% responderam ter preocupação com homicídios (índice de resposta mais alto para esse tipo de violência entre todos os setores). Nas regiões com domicílios em zonas de menor vulnerabilidade, o perigo da violência $(\mathrm{C}, \mathrm{D}, \mathrm{E}$ e F $)$ concentra-se nas opções roubos, furtos e assaltos, com respostas em torno de $90 \%$ para essas opções.

Quando perguntados sobre se alguém do domicílio já foi afetado pela violência, destacam-se as regiões menos vulneráveis - A, B, C, D, E, F, J e L - com respostas situadas entre $20 \%$ e $30 \%$ de afirmações positivas.

Outro aspecto que demarca o estigma social das regiões mais pobres é a percepção de que morar no bairro dificulta a conquista de um emprego, acesso a um serviço ou crediário. Chama a atenção a resposta das áreas $\mathrm{G}$ e N, em que $30 \%$ e $78 \%$ dos respondentes, respectivamente, percebem o estigma do lugar atrapalhando a busca pelo emprego e $17 \%$ e $64 \%$ afirmando que atrapalha no atendimento das compras e busca por crediário. $\mathrm{O}$ que parece ser muito preocupante se considerarmos a estrutura social, ainda que simbolicamente, centrada no emprego formal e na concepção de periferia, considerando aí seus efeitos sobre a evasão e o desempenho escolar, como demonstrado por Flores (2008). 


\section{Lazer e Cultura}

O espaço amplamente frequentado por jovens e adultos independentemente da região em que vivem são os shoppings centers, com respostas próximas a $90 \%$ de frequência. Entre os jovens de 15 a 24 anos aparecem também, muito próximas a esta, a ida ao cinema (o que está diretamente ligado aos shoppings) e shows. Interessante ressaltar que a gama de alternativas (pergunta direta sobre ir ou não ir a determinado espaço) ainda contava com passeios a teatros, exposições, museus, rodeios, praia, parques, represas, bares, festas, reuniões, organizações religiosas ou profissionais e cursos (informática, inglês, trabalhos manuais).

Em relação ao tempo livre, quando os maiores de 17 anos são questionados sobre o que fazem quando dispõem desse tempo (quando não estão no trabalho ou escola), $76 \%$ ficam em casa com outras atividades.

Essas questões expandem os limites da discussão da heterogeneidade como fator impactante no desempenho escolar (Alves; Franco; Ribeiro, 2008; Kaztman; Retamoso, 2005), trazendo para a discussão a capacidade de sociabilidade que os ambientes de convivência coletiva propiciam.

\section{DESEMPENHO E LOCALIZAÇÃO ESPACIAL DAS ESCOLAS}

Dentro do projeto "Estudo longitudinal sobre qualidade e eficácia no ensino fundamental brasileiro: GERES 2005”, como já comentado anteriormente, o desenho metodológico longitudinal permitiu que uma mesma amostra de alunos fosse observada ao longo dos quatro anos iniciais do ensino fundamental (à época da $1^{\text {a }}$ série até $4^{\mathrm{a}}$ série), dando um panorama acerca do que aprende nos diferentes anos um mesmo grupo de alunos (painel).

O instrumento cognitivo aplicado foi preparado pela equipe ${ }^{11}$ envolvida na pesquisa (Franco; Brooke; Alves, 2008):

Testes adequados aos anos iniciais do ensino fundamental foram preparados com base em matrizes de habilidades de Leitura e Matemática, por especialistas de três das universidades participantes da pesquisa, a UFMG, a PUC-Rio e a UFJF. Os itens utilizados foram previamente testados em escolas públicas e privadas das cidades de Juiz de Fora e Rio de Janeiro. Em cada onda, ${ }^{12}$ todos

11 As proficiências dos alunos GERES são recalculadas a cada onda, o que permite a comparação das diferentes ondas. Todos os cálculos das proficiências em todas as ondas são feitos pela mesma equipe, usando a mesma metodologia, o que garante a confiabilidade dos resultados cognitivos obtidos.

12 As ondas representam cada momento de medição da pesquisa longitudinal. Para maiores detalhes: <http://www.geres.ufmg.br/>. 
os alunos presentes foram submetidos tanto ao teste de leitura quanto ao de matemática. De modo a maximizar a discriminação dos testes, foram preparadas duas versões em cada onda, uma mais fácil e outra mais difícil. As diferentes versões dos testes (dentro e entre ondas) possuíam itens comuns, de modo a viabilizar escores equalizados a partir da Teoria de Resposta ao Item (TRI). (p. 633)

Os resultados, apurados em termos de valor agregado pelos alunos, permitem a comparação com uma escala de proficiência que possui níveis com descritores pedagógicos para cada um destes, sendo que o intervalo entre eles, mudança de nível, ocorre a cada 25 pontos na escala:

Em consonância com as matrizes de leitura e matemática, foram desenvolvidas duas escalas para descrever o desempenho dos alunos em termos das habilidades em fase de consolidação e as que já foram dominadas. Estas escalas, indispensáveis para a comunicação dos resultados às escolas e a interpretação pedagógica do desempenho das turmas, permitem mostrar a proporção de alunos em cada faixa ou nível de desempenho e comparar as escolas e redes em termos dessas proporções. (idem, ibidem)

Relacionando os dados acerca do valor agregado em leitura e matemática das 14 escolas aqui selecionadas, entre a primeira e a quinta onda do Projeto GERES-Campinas, temos a seguinte distribuição das escolas na escala de proficiência:

Tabela 4 - Distribuição das escolas estudadas na escala de proficiência do GERES

\begin{tabular}{l|r|r|r|r|r|r|r|r}
\hline & \multicolumn{4}{|c|}{ Valor agregado leitura } & \multicolumn{3}{c}{ Valor agregado matemática } \\
\cline { 2 - 9 } & Ano1 & Ano2 & Ano3 & Ano4 & Ano1 & Ano2 & Ano3 & Ano4 \\
\hline Escola A & 22,61 & 18,86 & 19,59 & 19,28 & 19,23 & 14,16 & 38,91 & 67,4 \\
Escola B & 27,2 & 11,16 & 20,3 & 15,1 & 27,45 & $-2,29$ & 39,75 & 71,99 \\
Escola C & 29,91 & 11,89 & 16,03 & 17,52 & 31,97 & 8,7 & 16,57 & 60,78 \\
Escola D & 29,36 & 13,06 & 16,87 & 10,98 & 23,9 & 15,39 & 55,85 & 35,08 \\
Escola E & 18,41 & 9,17 & 16,7 & 9,03 & 18,58 & 5,91 & 37,75 & 34,58 \\
Escola F & 30,48 & 13,41 & 12,78 & 14,91 & 27 & 6,9 & 39,58 & 49,76 \\
Escola G & 21,93 & 16,19 & 15,98 & 15 & 23,55 & 13,1 & 33,22 & 48,61 \\
Escola H & 18,97 & 9,69 & 14,1 & 7,64 & 38,96 & 19,37 & 29,43 & 24,43 \\
Escola I & 27,83 & 10,37 & 20,93 & 13,21 & 25,82 & 21,98 & 29,24 & 53,35 \\
Escola J & 21,19 & 13,25 & 18,12 & 12,98 & 27,67 & 10,77 & 46,66 & 41,35 \\
Escola K & 24,8 & 17,34 & 15,16 & 16,2 & 25,04 & 3,04 & 38,33 & 48,65 \\
Escola L & 31,41 & 11,11 & 22,78 & 7,76 & 24,29 & 9,55 & 53,43 & 45,85 \\
Escola M & 28,39 & 12,58 & 18,43 & 12,85 & 32,27 & 14,59 & 45,7 & 40,77 \\
Escola N & 18,73 & 9,89 & 17,44 & 12,63 & 30,06 & $-2,95$ & 33,83 & 50,67 \\
\hline
\end{tabular}

Fonte: Dados obtidos da pesquisa GERES 2005. 
$\mathrm{O}$ ano 1 corresponde à segunda medição do projeto GERES, realizada em novembro de 2005, demonstrando o quanto as escolas participantes agregaram em relação à entrada dos alunos na rede escolar medida em março de 2005. Nota-se certa regularidade na distribuição do valor agregado nas diferentes escolas. Os gráficos a seguir, já separados por avaliações de leitura e matemática, demonstram com mais clareza essa tendência da variação na proficiência média das escolas, outra forma de observar o valor agregado.

Mais do que demonstrar as diferenças entre as escolas analisadas (mais bem visualizado na tabela do valor agregado), a distribuição da proficiência em leitura nas cinco ondas do projeto GERES, Figura 2, mostra de forma geral um padrão bastante definido de crescimento na escala de proficiência, um crescimento acentuado entre a primeira e segunda ondas (a taxas crescentes) e um crescimento mais moderado a partir da terceira onda (a taxas decrescentes). Surpreende a proficiência de entrada dos alunos no sistema escolar (onda $1^{13}$ ), pois se concentra no nível 3 da escala de habilidades (entre 75 e 100 pontos), o que significa crianças em pleno desenvolvimento de importantes habilidades relativas à apropriação de palavras e frases em tarefas simples de leitura.

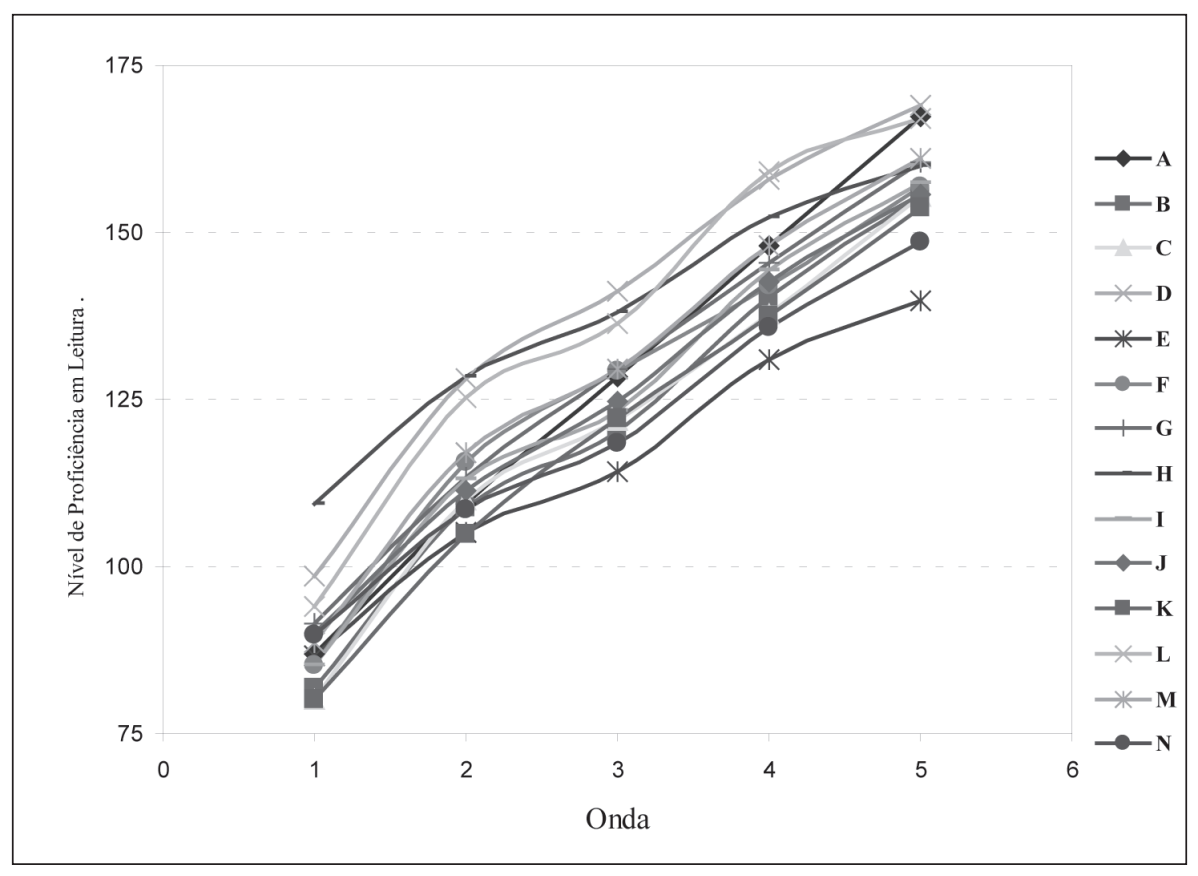

Figura 2: Proficiência das escolas em leitura

Fonte: Dados elaborados a partir das pesquisas GERES 2005 e vulnerabilidade.

13 A medida da onda 1 foi feita em março de 2005 e corresponde ao valor absoluto da medição. 
Se sairmos da visão geral de tendência e observarmos detidamente cada escola, destaca-se do padrão a escola $\mathrm{D}$, que está no limite superior da escala (98,7 pontos) e localizada em uma área de baixa vulnerabilidade, sendo que a maioria se situa entre 80 e 90 pontos; e a escola $H$, que com 109,41 pontos já atinge o nível de proficiência 4 (crianças que estão no auge do desenvolvimento da habilidade de compreensão da natureza alfabética do sistema de escrita) e está situada em uma área de vulnerabilidade absoluta.

Já no final do primeiro ciclo do ensino fundamental (onda 5), a média das crianças de todas as escolas não consegue atingir o nível 8 (acima de 200 pontos), que representaria a consolidação de leitura e interpretação de elementos textuais explícitos em textos mais longos. Mas já há uma dispersão maior entre os resultados das escolas, mesmo considerando que a diferença entre o melhor resultado e o pior resultado se mantenha em torno de 30 pontos (aproximadamente um nível na escala).

Chamam a atenção as escolas $\mathrm{E}$ e $\mathrm{N}$, que ficaram no nível de proficiência 5 (entre 125 e 150 pontos, crianças que estabilizaram a habilidade de codificação e decodificação apresentando maior independência em relação a leitura), sendo que a escola E está na área de mais baixa vulnerabilidade da pesquisa e a escola $\mathrm{N}$ localizada na região que demonstrou ter as condições mais vulneráveis da pesquisa.

Entre o grupo que ficou no nível de proficiência 6 (entre 150 e 175 pontos, crianças que passam a lidar com gêneros textuais de diferentes níveis de circulação social), podemos destacar a escola $\mathrm{A}$, localizada em uma região de vulnerabilidade relativa alta, que manteve durante as cinco ondas uma tendência de crescimento acentuado (crescimento estável, como demonstra a Tabela 4), obtendo a maior diferença absoluta entre a onda 1 e 5; e as escolas D e H, que se destacavam na primeira onda e que tiveram tendências diferentes, sendo que a escola D (zona 3, área de vulnerabilidade relativa média) teve a maior proficiência média final (168,97 pontos) e a escola $\mathrm{H}$ (zona 1, área de vulnerabilidade absoluta) teve o pior crescimento, galgando apenas dois níveis de proficiência entre a onda 1 e 5 (50,4 pontos na tabela de valor agregado). 


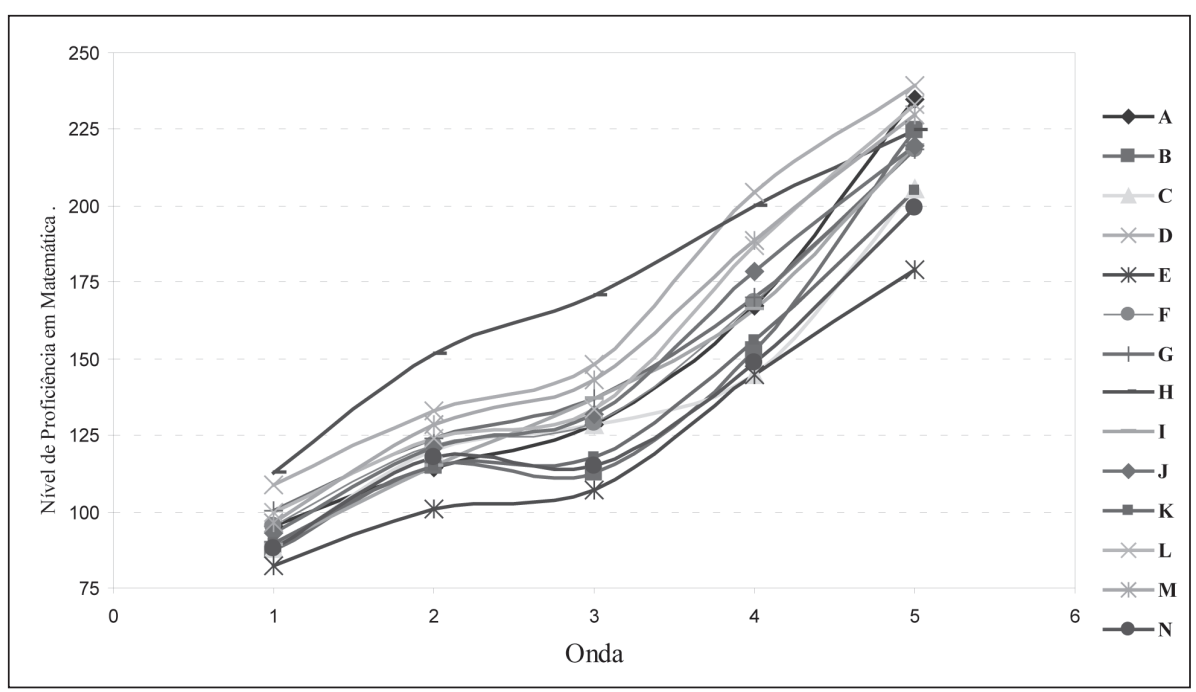

Figura 3: Proficiência das escolas em matemática

Fonte: Dados elaborados a partir das pesquisas GERES 2005 e vulnerabilidade.

A distribuição geral da proficiência em matemática nas cinco ondas do projeto GERES, Figura 3, mostra um padrão definido de crescimento na escala de proficiência, um crescimento acentuado entre a primeira e segunda ondas (a taxas crescentes), uma estagnação entre a segunda e terceira ondas (não crescimento e até decrescimento) e um crescimento muito acentuado a partir da terceira onda (a taxas crescentes). Mais uma vez, surpreende a proficiência de entrada dos alunos no sistema escolar (onda 1), pois como destaca Ubriaco (2009) em trabalho que analisa as escalas de proficiência dos alunos que participaram do GERES: "Os resultados mostram que a maioria dos alunos $(63,1 \%)$ está situada no nível Básico, o que pressupõe que os mesmos já possuíam alguns conhecimentos prévios de matemática, tendo sido estes adquiridos na Educação Infantil ou através de situações quotidianas informais" (p. 87).

Nas demais observações sobre a proficiência em matemática, repete-se o que foi descrito na proficiência em leitura.

Em razão desse padrão de distribuição e da proximidade de proficiência de leitura ou de matemática das escolas pesquisadas, não encontramos uma relação linear que possa claramente relacionar, por exemplo, regiões mais vulneráveis a baixo desempenho das escolas. Considerando a média de proficiência das escolas que compõem cada zona e as agrupando, podemos notar a representação gráfica dessa similaridade de tendência, como demonstrado nas Figuras 4 e 5. 


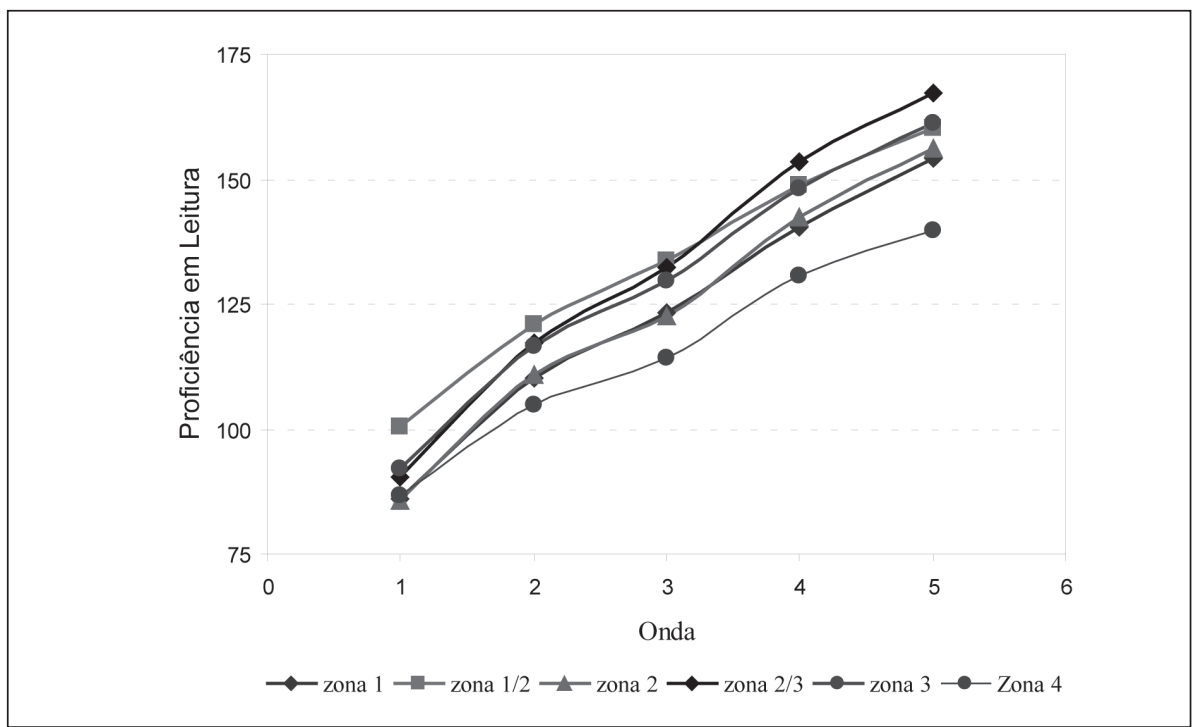

Figura 4: Proficiência em leitura por zona de vulnerabilidade

Fonte: Dados elaborados a partir das pesquisas GERES 2005 e vulnerabilidade.

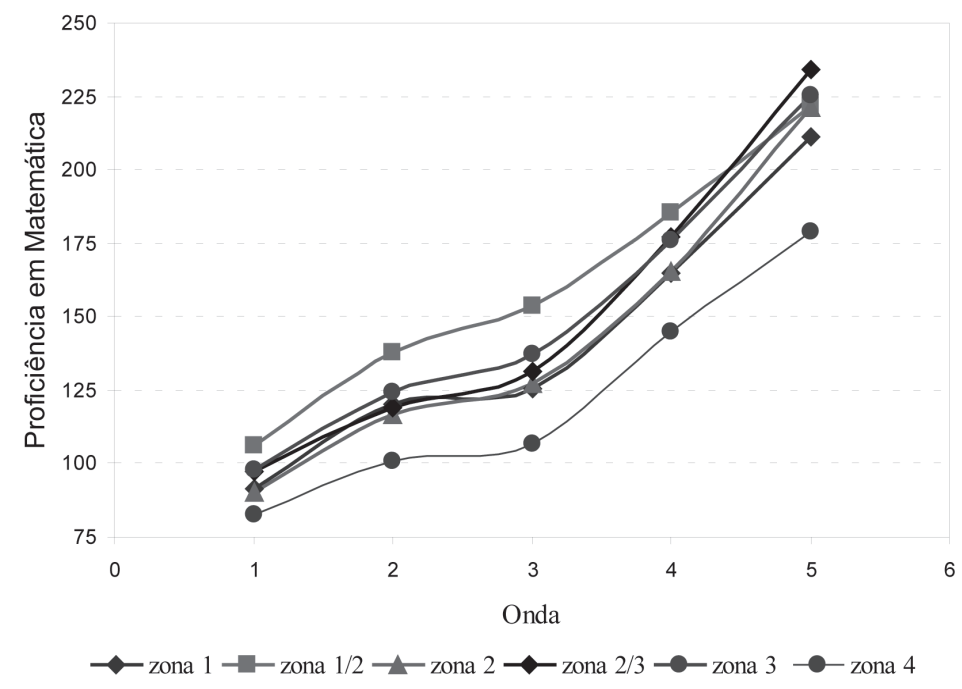

Figura 5: Proficiência em matemática por zona de vulnerabilidade

Fonte: Dados elaborados a partir das pesquisas GERES 2005 e vulnerabilidade. 
Vale ressaltar, todavia, que a curva correspondente à zona 4 (baixa vulnerabilidade) não permite uma análise mais precisa por conter apenas uma escola representante e haver evidências de que, assim como na experiência apresentada por Alves, Franco e Ribeiro (2008) em relação à cidade do Rio de Janeiro, localiza-se nas proximidades de uma ocupação, sendo provável receber alunos provindos dessa área e não dos setores censitários que correspondem aos dados coletados para o mapeamento das zonas.

\section{DIALOGANDO COM AS PESQUISAS DA ÁREA}

O fato de não haver uma recorrência clara em relação à disposição espacial das escolas relacionada ao seu desempenho medido pelo valor agregado nos distancia de alguns estudos, como os apresentados em Ribeiro e Kaztman (2008), que encontram na distribuição espacial dos sujeitos e escolas elementos diretamente relacionados aos resultados educacionais deles. As análises foram feitas a partir de diferentes elementos de escolarização (como defasagem idade-série, conclusão do ensino médio e desempenho em avaliações de larga escala) em relação ao território ocupado (seja ele entendido a partir do nível socioeconômico, segregação espacial ou vulnerabilidade social).

Exemplo dessa tendência de análise confirma-se no texto de Suárez e Groisman (2008), que, utilizando-se de uma triangulação de métodos (indicadores de segregação, multinominais e hierárquico linear) e de dados (pesquisa de amostra de domicílios, avaliação nacional e pesquisa com diretores de escola), concluem que, em Buenos Aires, as disposições espaciais segregadas também se correlacionam com dificuldades de aprendizagem escolar e condições de infraestrutura das escolas.

Ainda na linha de defesa do efeito-vizinhança, Torres, Ferreira e Gomes (2005), analisando o município de São Paulo, indicam que o fator socioespacial influi nos índices de conclusão do ensino médio (sendo potencializado se houver fatores associados como cor e gênero, além do NSE, que é o fator mais determinante juntamente com escolaridade da mãe), gerando os chamados "Paradoxos da universalização"; mais crianças com acesso a escola em bairros com menor estrutura não se configura em aprendizagem (qualidade), o que preocupa pelo efeito de transmissão intergeracional das dificuldades com a escolarização.

$\mathrm{O}$ artigo indica que a performance escolar dos mais pobres é influenciada pelos demais, mas é frequente que famílias de baixa renda só consigam matricular seus filhos em escolas relativamente homogêneas (relação direta com a segregação territorial). A partir dos dados analisados, os autores concluem que, independentemente da renda familiar, morar na periferia representa uma desvantagem adicional em relação a concluir o ensino médio, e nela as dinâmicas do local de moradia e as escolas não podem ser separadas por fazerem parte de uma mesma dinâmica de segregação residencial. 
Deixando de lado a expectativa por encontrar fatores associados e tentando identificar características institucionais das escolas da cidade de São Paulo que possam reforçar os efeitos de segregação espacial, Torres et al. (2008) indicam uma significativa diferença entre a rede municipal (que possui mais acesso a serviços de transporte e infraestrutura) e a rede estadual (que possui um período maior de permanência dos estudantes na escola).

A partir de entrevistas em profundidade (grupos focais) com oitenta professores, encontrou-se também um efeito "segregação de professores" menos preparados e inexperientes que, pelo processo de atribuição de aulas (mesmo havendo incentivos financeiros para anular esse efeito), acabam por concentrar-se nas escolas da periferia. Foi identificado inclusive que esses professores alimentam um forte estigma (preconceito) e acabam por desestimular ainda mais as crianças provindas de regiões mais pobres, quanto a sua trajetória escolar. Interessante destacar que os pesquisadores deste trabalho afirmam que estudar as condições institucionais das escolas (redes e professores) permite focalizar o problema de forma que as políticas públicas possam agir rapidamente.

Em parte, o mesmo ponto de vista é compartilhado por Barbosa (2009), que, a partir de pesquisas realizadas com escolas de Belo Horizonte, analisando diferenças de programas estaduais e municipais de reforma educacional, justifica a importância de se pensar o efeito-escola e o fato de que escolas também geram desigualdades (para além das tradicionais análises que concluem que a pobreza tem efeito sobre a situação escolar das crianças), já que não se podem mudar as desigualdades sociais e de renda a partir de políticas públicas.

Luco e Engel (2008) iniciam seu texto defendendo, com base no caso do Chile, que os resultados de diversas abordagens de índices de segregação residencial, utilizando a escolaridade dos pais ou os resultados de provas de desempenho nacionais e internacionais (SIMCE e TIMSS), mostram uma segmentação escolar estratificada socialmente, com piores resultados entre estudantes da população com maior vulnerabilidade social se comparados os efeitos de bairro. Segundo os autores, a análise dos bairros desfaz o efeito de homogeneização em análises que consideram áreas metropolitanas desenvolvidas, o que já se confirmou em vários estudos de estratificação, pois existe grande heterogeneidade nas metrópoles, sendo necessário uma preocupação com as escalas.

Porém, comparando suas análises com outros autores da mesma publicação (que participaram de um evento de especialistas no tema, no Observatório das Metrópoles no Rio de Janeiro), Luco e Engel (2008) inferem que é importante relativizar os efeitos de vizinhança com possíveis efeitos da escola sobre os desempenhos dos estudantes.

Em um estudo que analisa a relação entre infraestruturas escolares, a média de desempenho escolar acadêmico, medido pelo Sistema de Avaliação de Rendimento Escolar do Estado de São Paulo (SARESP), e a localização das escolas estaduais de Campinas, Cunha et al. (2009) percebem que: 
[...] escolas estaduais localizadas em áreas de concentração de pobreza têm menor realização acadêmica em testes de matemática (e escolas localizadas em áreas de concentração de riqueza têm melhores notas em Português) que as áreas não segregadas da cidade, mesmo considerando que estas escolas são todas administradas pela mesma esfera de governo. (p. 874, tradução nossa)

Como essa sintética relação de trabalhos demonstra, existe uma grande diversidade de estudos que procuram evidenciar o efeito-vizinhança e o efeito-escola, utilizando diferentes abordagens, metodologias e instrumentos, tentando, em geral, medir esses efeitos sobre determinados objetivos escolares. Para concluir a análise apresentada neste artigo, pretendemos utilizar essa pequena e diversa amostra de estudos relacionados ao tema de modo a que se contrua um diálogo com essas pesquisas para refletir sobre os limites e possibilidades da experiência analítica que expusemos.

A primeira questão é temporal, pois, como aponta Silva (2003), os processos de expansão escolar têm uma tendência de reforço às desigualdades no processo de estratificação educacional. No primeiro momento de expansão de atendimento a determinado nível de ensino, as vantagens decorrentes da expansão favorecem aqueles que já possuem vantagens relativas, ou seja, os mais pobres possuem uma diversidade de dificuldades que os impedem de acessar completamente os benefícios da expansão educacional.

Essa evidência demonstra que é fundamental compreender o processo histórico de constituição dos sistemas escolares, a história da educação e dos processos sociais a ela relacionados, quando tentamos construir um modelo explicativo de resultados escolares, seja ele para explicar o efeito-vizinhança ou o efeito-escola. Dessa evidência decorre outra; as análises de estratificação social, que têm como objeto questões educacionais, necessitam de instrumento teórico e metodológico que consiga melhorar a capacidade diagnóstica da heterogeneidade do espaço e dos grupos sociais, daí a pertinência de investir no desenvolvimento do modelo de vulnerabilidade social.

Pensando nos instrumentos de avaliação que são utilizados como parâmetro de sucesso escolar, um aspecto que pode explicar o fato de não termos encontrado em nossa experiência analítica diferenças significativas entre as escolas com base na localização pode ser atribuído ao instrumento de coleta de dados empregado, já que os dados que utilizamos neste artigo foram retirados de uma pesquisa longitudinal tipo painel. Os dados usualmente utilizados nesse tipo de comparação são obtidos a partir de medições transversais, as quais podem estar medindo o efeito de entrada e não o desenvolvimento no período escolar, corroborando o equívoco de se analisar o desempenho escolar pontualmente e aumentando a probabilidade de a medição não representar uma tendência do desenvolvimento do estudante. Isso sem contar os efeitos indiretos no ensino que as avaliações de sistema criam na sua aplicabilidade ${ }^{14}$.

14 Como os sistemas de avaliação em maior ou menor grau geram consequências de prestígio e, em alguns casos, de financiamento das escolas, há todo um processo de 
Ainda dentro desse diálogo das características dos instrumentos de avaliação que utilizamos e outros estudos, notamos que geralmente são utilizados dados de avaliações de sistema que são padronizados a partir de uma escala de proficiência montada em torno de habilidades descritas em uma matriz de referência, ou seja, há um sentido pedagógico do estágio de desenvolvimento cognitivo representado nessas escalas. Porém, todos os estudos aqui apresentados acabam por comparar apenas os desvios em torno da média ou acréscimos com variação e significância estatística relacionada às variáveis independentes utilizadas (o efeito de ser de determinada rede, ter pais com certa escolaridade, infraestrutura da escola...).

O efeito gerado pela falta de interpretação pedagógica das escalas poderia, por exemplo, ter nos levado a outros resultados em nossa experiência analítica (ver como a pesquisa GERES 2005 montou sua escala de proficiência), talvez supervalorizando o efeito espacial da distribuição das escolas. Pois, afinal, variar 10, 20, $50 \mathrm{ou}$ 100 pontos em uma escala de proficiência só tem significado quando referenciado por uma interpretação pedagógica.

Pensando nas discussões de efeito-vizinhança e efeito-escola, não como campo de poder que disputa a legitimidade das explicações do desempenho escolar, nossa perspectiva aproxima-se muito das considerações de Soares, Rigotti e Andrade (2008), que afirmam que essa distribuição heterogênea no espaço, ao mapearmos o valor agregado das escolas e sua localização territorial, pode significar tanto que a escola, em si, é o fator que determina a aprendizagem das crianças (efeito-escola) sem que a localização espacial interfira de forma contundente, como que algumas instituições se abram mais ao seu entorno, fortalecendo o processo de aprendizagem. Isso porque, ao assumir a região em que os alunos vivem, a escola poderia potencializar as alternativas de trabalho, apropriando-se das características locais para o desenvolvimento de suas práticas, maximizando a possibilidade de aprendizagem presente nelas e a partir delas.

Ou, ainda, descrita como hipótese explicativa apontada por Flores (2008) quando indica que, embora haja a percepção em seus estudos de que a moradia em locais de alta vulnerabilidade é negativa para o desempenho educacional, há escolas que poderiam ajudar as crianças a "resistir ao efeito negativo do bairro, acumulando os ativos necessários para aproveitar as oportunidades que ela [escola] lhes oferece" (p. 176).

Nesse sentido, alguns casos chamam a atenção:

- Como a escola A, mesmo localizada em uma região de vulnerabilidade relativa alta, manteve durante as cinco ondas uma tendência de crescimento

preparação das escolas para os exames, o que inclui um reforço e a indução de separar alunos de melhor desempenho em determinadas turmas e até mesmo escolas. 
acentuado (a taxas crescentes), obtendo a maior diferença absoluta entre a onda 1 e 5 ?

- Por que as escolas D (área de vulnerabilidade relativa média) e H (área de vulnerabilidade absoluta) que se destacavam na primeira onda tiveram tendências diferentes (a escola $\mathrm{D}$ com melhor desempenho final e a escola $\mathrm{H}$ com o pior crescimento, galgando apenas dois níveis de proficiência, em leitura, entre a onda 1 e 5$)$ ?

- Como explicar, apenas com os dados do levantamento de desempenho e localização, o resultado tão baixo e próximo das escolas $\mathrm{E}$ e N, sendo que a escola $\mathrm{E}$ está em uma área de baixa vulnerabilidade (a única escola da zona 4 na pesquisa) e a escola $\mathrm{N}$, localizada na região que demonstrou ter as condições mais vulneráveis da pesquisa?

O trabalho aqui desenvolvido teve como objetivo refletir sobre a distribuição de escolas municipais da cidade de Campinas-SP com base em sua localização espacial e desempenho escolar. Entendemos que a partir dele podemos tirar importantes considerações para o desenvolvimento de estudos que utilizam metodologias e proposições análogas às aqui expostas.

As características levantadas expõem regiões precárias no que concerne à infraestrutura, como ruas não asfaltadas, recebimento não contínuo de água, rede de esgoto inexistente, falta de coleta diária de lixo e proximidade de rios e córregos que, juntas, geram condições sanitárias e de saúde que podem interferir diretamente na saúde e na frequência escolar das crianças que vivem nessas regiões. Famílias com quantidades de analfabetos e não concluintes do primeiro ciclo do ensino fundamental e com pouco acesso a espaços educativos não escolares e ambientes de socialização mais heterogêneos. Regiões marcadas pela violência (homicídios e tráfico de drogas) e que sofrem estigmas de lugar. Será mesmo possível comparar essas desigualdades em questões básicas de seguridade social tendo como parâmetro apenas o desempenho escolar?

Encontrar razões para o desempenho escolar é uma tarefa extremamente complexa, pois revela uma tendência dos estudos das ciências sociais em adaptar preferências por métodos descritivos e quantitativos na explicação de fenômenos relacionados à interação entre o homem e o espaço habitado. Essa tendência demonstra-se sempre incompleta, pois a apropriação da realidade pelo modelo é tarefa incessante e sempre referenciada por uma metodologia e racionalidade que a condicionam. O que revela, por exemplo, uma tendência constante de condicionantes socioeconômicos serem na maior parte das vezes a variável que mais explica o comportamento dos fenômenos sociais.

Nem por isso se faz inútil ou paralisante o exercício de buscar explicações para o desempenho escolar em várias frentes (psicologia, pedagogia, sociologia, história, urbanismo). Neste estudo, procuramos levantar características vinculadas 
à condição espacial a uma medida de desempenho dos estudantes de determinadas escolas para identificar possíveis correlações e inferências.

O levantamento revelou uma grande heterogeneidade de condições espaciais, sejam elas observadas a partir de zonas de vulnerabilidade demarcadas por características físicas, de capital humano ou social, ou ainda, considerando uma porção mais reduzida do espaço habitado, os setores censitários.

Toda essa diversidade exige, sem dúvida, um olhar mais atento e cuidadoso para além do que foi observado neste ensaio. Ainda assim vale indicar que:

- A baixa correlação para definir uma tendência explícita de efeitos de lugar e desempenho escolar, pelo menos de maneira mais geral, pode não significar que ela não exista a priori. Pois a natureza e o contexto do fenômeno, como observado, não permitem uma relação linear de causa e efeito, exigindo um maior trabalho de seleção de categorias que possam produzir comparabilidade.

- Casos extremos, como os das regiões das escolas K e N (desempenhos extremos em leitura dentro da mesma zona de vulnerabilidade), tal qual comparações entre as áreas E e N (desempenhos iguais dentro de zonas distintas de vulnerabilidade), podem servir como variáveis de controle importantes para revelar características explicativas para o fenômeno do desempenho. $\mathrm{Ou}$, ainda, escolas como $\mathrm{C}$ e E, que estão distantes apenas $1 \mathrm{~km}$ uma da outra e tiveram proficiência muito próxima na onda 1 , mas chegaram à onda 5 com diferença de um nível de proficiência. São exemplos que sugerem uma pesquisa mais focalizada (em relação às regiões) e abrangente (em relação aos referenciais e métodos de observação).

- Dado o custo e o tempo de retorno dos dados, a maioria das pesquisas emprega dados censitários para caracterizar os espaços, grupos e elementos que serão utilizados para comparação com o desempenho escolar, que também, geralmente, são retirados de pesquisas nacionais de proficiência ou censos escolares, diferentemente deste ensaio que, como foi explicado na descrição das pesquisas utilizadas, gera possibilidades analíticas bastante promissoras.

- Diferentemente do viés colocado pela maioria das pesquisas que relacionam segregação espacial e vulnerabilidade, que orienta as políticas públicas no sentido de ações focadas para solucionar distorções e desigualdades sociais, como em Marques e Torres (2005) e Barbosa (2009), nosso enfoque reforça a concepção da necessidade de universalização de direitos e políticas sociais, deixando que estudos de efeito-escola e vizinhança sejam instrumentos de diagnóstico e auxílio aos gestores públicos, sem intencionar que essas pesquisas se configurem como orientação direta de políticas.

Essas observações somente poderiam ser compreendidas, confirmadas ou refutadas a partir de mais estudos sobre o fenômeno, articulados com uma meto- 
dologia qualitativa que permitisse conhecer não só as características da localidade e da escola, como a maneira como a relação entre elas é estabelecida.

\section{REFERÊNCIAS}

Alves, Fátima; Franco, Creso; Ribeiro, Luiz Cesar de Queiroz. Segregação residencial e desigualdade escolar no Rio de Janeiro. In: Ribeiro, Luiz Cesar de Queiroz; KazTMAn, Ruben. A cidade contra a escola?: segregação urbana e desigualdades educacionais em grandes cidades da América Latina. Rio de Janeiro: Letra Capital, FAPERJ; Montevidéu: IPPES, 2008. p. 91-118.

Alves, Maria Tereza Gonzaga; SoAres, José Francisco. As pesquisas sobre os efeitos das escolas: contribuições metodológicas para a sociologia da educação. Sociedade e Estado, Brasília, v. 22, n. 2, p. 435-473, maio/ago. 2007a.

. Efeito-escola e estratificação escolar: o impacto da composição de turmas por nível de habilidade dos alunos. Educação em Revista, Belo Horizonte, v. 45, p. 25 58, jun. 2007b.

Andrade, Luciana Teixeira de et al. O efeito-vizinhança e o efeito-escola na explicação do desempenho escolar. In: 32 ENCONTRO ANUAL DA ANPOCS, out. 2008. Resumo expandido. Disponível em: <http://200.152.208.135/anpocs/trab/ adm/resumo_trabalho.tpl.php?id_trabalho $=1605 \&$ PHPSESSID $=$ ac160d430ba847 fa45acf61382daaa79>. Acesso em: 24 mar. 2009.

Barbosa, Maria Ligia de Oliveira. Desigualdade e desempenho: uma introdução a sociologia da escola brasileira. Belo Horizonte: Argvmentum, 2009.

BiLAC, Elisabete Dória. Gênero, vulnerabilidade das famílias e capital social: algumas reflexões. In: Cunha, José Marcos Pinto da (Org.). Novas metrópoles paulistas: população, vulnerabilidade e segregação. Campinas: NEPO/UNICAMP, 2006. p. 51-65.

Bichir, Renata Mirandola; Torres, Haroldo da Gama; Ferreira, Maria Paula. Jovens no município de São Paulo: explorando os efeitos das relações de vizinhança. Revista Brasileira de Estudos Urbanos e Regionais (ANPUR), v. 6, n. 2, p. 53-69, 2005. Bressoux, Pascal. As pesquisas sobre o efeito-escola e o efeito-professor. Educação em Revista, Belo Horizonte, FAE/UFMG, n. 38, p. 17-88, 2003.

Brooke, Nigel; Soares, José Francisco (Org.). Pesquisa em eficácia escolar origem e trajetórias. Belo Horizonte: Editora UFMG, 2008.

Cunha, José Marcos Pinto et al. Novas metrópoles paulistas: população, vulnerabiliade e segregação. Campinas: Vulnerabilidade, 2006a. Disponível em: <http://www.nepo. unicamp.br/textos/publicacoes/livros/vulnerabilidade/index.htm>. Acesso em: 25 ago. 2009. 
. Expansão metropolitana, mobilidade espacial e segregação nos anos 90: o caso da RM de Campinas. In: Cunha, José Marcos Pinto (Org.). Novas metrópoles paulistas: população, vulnerabilidade e segregação. Campinas: UNICAMP, p. 337-363, 2006b.

Social segregation and academic achievement in state-run elementary schools in the municipality of Campinas, Brazil. Geoforum, v. 40, p. 873-883, 2009. Flores, Carolina. Segregação residencial e resultados educacionais na cidade de Santiago do Chile. In: Ribeiro, Luiz Cesar de Queiroz; Kaztman, Ruben. A cidade contra a escola?: segregação urbana e desigualdades educacionais em grandes cidades da América Latina. Rio de Janeiro: Letra Capital, FAPERJ; Montevidéu: IPPES, 2008. p. 145-179.

Foreuin, Jean-Claude. Sociologia da educação: dez anos de pesquisa. Petrópolis: Vozes, 1995. Franco, Creso. O SAEB: potencialidades, problemas e desafios. Revista Brasileira de Educação, v. 17, p. 127-133, 2001.

; Brooke, Nigel; Alves, Fátima. Estudo longitudinal sobre qualidade e equidade no ensino fundamental brasileiro: GERES 2005. Ensaio: Aval. Pol. Públ. Educ., Rio de Janeiro, v. 16, n. 61, p. 625-638, out./dez. 2008. Disponível em: <http:// www.scielo.br/pdf/ensaio/v16n61/v16n61a08.pdf >. Acesso em: ago. 2009.

Hogan, Daniel J.; Marandola JR., Eduardo. Para uma conceituação interdisciplinar da vulnerabilidade. In: CunHA, José Marcos Pinto (Org.). Novas metrópoles paulistas: população, vulnerabilidade e segregação. Campinas: NEPO/UNICAMP, 2006. p. 23-50.

KazTMan, Ruben. Notas sobre la medición de la vulnerabilidad social. Borrador para discusión. 5 Taller regional, la medición de la pobreza, métodos e aplicaciones. México: BID-BIRF-CEPAL, 2000. Disponível em: <www.eclac.cl/deype/noticias/ proyectos>. Acesso em:

; Retamoso, Alejandro. Segregación espacial, empleo y pobreza en Montevideo. Revista de la CEPAL, n. 85, Santiago de Chile, abr. 2005. Disponível em: <http://www.eclac.cl/publicaciones/xml/8/21048/lcg2266eKaztmanRetamoso. pdf>. Acesso em: 9 nov. 2009.

Kowarick, Lucio. Viver em risco: sobre a vulnerabilidade no Brasil urbano. Novos Estudos CEBRAP, São Paulo, n. 63, p. 9-30, jul. 2002.

Lipton, Michael; MaXwell, Simon. The new poverty agenda: An overview. Discussion Paper 306. Institute of Development Studies, Brighton, 1992.

Luco, Camilo Arriagada; Engel, Yael Korol. Desafios às políticas educacionais que surgem com as novas tendências à segregação urbana. In: Ribeiro, Luiz Cesar de Queiroz; KazTMAn, Ruben. A cidade contra a escola?: segregação urbana e desigualdades educacionais em grandes cidades da América Latina. Rio de Janeiro: Letra Capital, FAPERJ; Montevidéu: IPPES, 2008. p. 309-326. 
Mareues, Eduardo; Torres, Haroldo da Gama (Org.). São Paulo: segregação, pobreza e desigualdade. São Paulo: Editora SENAC, 2005.

Moser, Caroline. Confronting crisis: A comparative study of household responses to poverty and vulnerability in four poor urban communities. Environmentally Sustainable Studies and Monograph Series, n. 8, Washington DC: World Bank, 1996.

. Household Responses to Poverty and Vulnerability. Washington DC: World Bank, 1997.

. The asset vulnerability framework: reassessing urban poverty reduction strategies. World Development, v. 26, n. 1, 1998.

Ribeiro, Luiz Cezar de Queiroz; KAZTMAn, Ruben. A cidade contra a escola: segregação urbana e desigualdades educacionais em grandes cidades da América Latina. Rio de Janeiro: Letra Capital, FAPERJ; Montevidéu: IPPES, 2008.

Rodríguez, Jorge. Vulnerabilidad demográfica: una faceta de las desventajas sociales. Série Población y Desarrollo, Santiago - Chile, Comisión Económica para América Latina y el Caribe (CEPAL), n. 5, 2000.

Santos, Milton. Espaço e sociedade. Petrópolis: Vozes, 1979.

Silva, Nelson do Valle. Expansão escolar e estratificação educacional no Brasil. In: Hasenbalg, Carlos A.; Silva, Nelson do Valle (Org.). Origens e destinos: desigualdades sociais ao longo da vida. Rio de Janeiro: IUPERJ/UCAM, Topbooks, 2003. p. 105-146. SoARES, José Francisco; Andrade, Renato Júdice de. Nível socioeconômico, qualidade e equidade das escolas de belo Horizonte. Ensaio: Aval. Pol. Públ. Educ. Rio de Janeiro, v. 14, n. 50, p. 107-126, jan./mar. 2006.

Soares, José Francisco; Rigotti, José Irineu Rangel; Andrade, Luciana Teixeira de. As desigualdades socioespaciais e o efeito das escolas públicas de Belo Horizonte. In: Ribeiro, Luiz Cesar de Queiroz; KAzTMAn, Ruben. A cidade contra a escola?: segregação urbana e desigualdades educacionais em grandes cidades da América Latina. Rio de Janeiro: Letra Capital, FAPERJ; Montevidéu: IPPES, 2008. p. 119-144.

Solis, Patrício. Efeitos do nível socioeconômico da vizinhança na continuidade escolar entre o ensino médio e o pré-universitário no México, Distrito Federal. In: Ribeiro, Luiz Cesar de Queiroz; KAZTMAn, Ruben. A cidade contra a escola?: segregação urbana e desigualdades educacionais em grandes cidades da América Latina. Rio de Janeiro: Letra Capital, FAPERJ; Montevidéu: IPPES, 2008. p. 223-244.

SuÁrez, Ana Lourdes; Groisman, Fernando. Segregação residencial e conquistas educacionais na Argentina. In: Ribeiro, Luiz Cesar de Queiroz; Kaztman, Ruben. A cidade contra a escola?: segregação urbana e desigualdades educacionais em grandes cidades da América Latina. Rio de Janeiro: Letra Capital, FAPERJ; Montevidéu: IPPES, 2008. p. 33-58.

Torres, Haroldo da Gama; Ferreira, Maria Paula; Gomes, Sandra. Educação e segregação social: explorando o efeito das relações de vizinhança. In: MARQUES, 
Eduardo; TorRes, Haroldo (Org.). São Paulo: segregação, pobreza e desigualdades sociais. São Paulo: SENAC, 2005.

Torres, Haroldo da Gama et al. Educação na periferia de São Paulo: como pensar as desigualdades educacionais? In: Ribeiro, Luiz Cesar de Queiroz; Kaztman, Ruben. $A$ cidade contra a escola?: segregação urbana e desigualdades educacionais em grandes cidades da América Latina. Rio de Janeiro: Letra Capital, FAPERJ; Montevidéu: IPPES, 2008. p. 59-90.

Ubriaco, Fabiana Esméria de Castro Alves. Interpretação de escalas de medida da competência matemática. 122f. Dissertação (Mestrado) - Universidade Federal de Minas Gerais, Faculdade de Educação, Belo Horizonte, 2009.

\section{SOBRE OS AUTORES}

Sergio Stoco é pesquisador associado do Núcleo de Estudos de Políticas Públicas (NEPP) e do Grupo de Redistribuição Espacial da População e Urbanização, ambos da Universidade Estadual de Campinas (UNICAMP). Pós-doutorando do Núcleo de Estudos de População (NEPO/UNICAMP).

E-mail: brestoco@hotmail.com

Luana Costa Almeida é doutoranda em educação pela Universidade Estadual de Campinas (UNICAMP).

E-mail: luanaca@gmail.com

Recebido em outubro de 2010 Aprovado em julbo de 2011 
Formación continuada de profesores para la diversidad cultural: éntasis, silencios y perspectivas

El articulo propone una perspectiva "culturalmente responsiva" como posibilidad desta formación, discutindo la producción del conecimiento en la area, en lo presente milenio, utilisando analise documental de los periódicos internacionales por lo sistema Qualis/ CAPES, mais especificamente, Cadernos de Pesquisa $y$ Revista Brasileira de Educação, y también de trabajos y ponencias de las runiónes anuales de la Associação Nacional de Pós-Graduação e Pesquisa em Educação (ANPEd), con el foco en los GTs de "Formação de Professores, Didática, Educação e Relaçôes Étnico-Raciais e Gênero, Sexualidade e Educação. Los resultados apresentán un panorama de la temática en la producción academica, problematizando silencios y apontando possibilidads y desafios, podendo contribuir para el desarollo da la formación de maestros para la diversidad cultural.

Palavras clave: formación continuada de profesores; diversidad cultural; multiculturalismo; producción del conocimiento.

\section{SERGIO STOCO E LUANA COSTA ALMEIDA}

\section{Escolas municipais de Campinas e vulnerabilidade sociodemográfica: primeiras aproximações}

Este trabalho discute a distribuição de escolas municipais de Campinas,SP, segundo sua localização espacial e desempenho escolar, tendo como fontes os dados às pesquisas: GERES 2005 - LOED / FE / UNICAMP < http://www.geres.ufmg. br/> e Vulnerabilidade - NEPO / UNICAMP <http://www.nepo.unicamp.br/ vulnerabilidade/>. Utilizando referenciais teóricos que sustentam os conceitos de Vulnerabilidade Social, Segregação Espacial, Efeito-Vizinhança e Efeito-Escola, analisamos a distribuição das escolas dentro das diferentes Zonas de Vulnerabilidade, relacionando essa distribuição aos resultados de seu desempenho medido pelo valor agregado. A metodologia utilizada se deu com: 1) a descrição das variáveis relacionadas às características do entorno das escolas; 2) o cruzamento das características encontradas e o desempenho dessas escolas. Os resultados revelaram que não há uma recorrência clara em relação à disposição espacial das escolas quando relacionadas ao seu desempenho.

Palavras-chave: vulnerabilidade social; desempenho escolar; segregação espacial; efeito-vizinhança.

\section{Municipal schools of Campinas and sociodemographic vulnerability: first approximations}

This paper discusses the distribution of public schools in Campinas, São PauloBrazil, according to their spatial location and school performance, as source of polling 
data: GERES 2005 - LOED / FE / UNICAMP < http://www.geres.ufmg.br/> and Vulnerability-NEPO/UNICAMP < http://www.nepo.unicamp.br/vulnerabilidade/>. Using theoretical references that support the concepts of Social Vulnerability, Spatial Segregation, Neighborhood Effects and School Quality, analyzed the distribution of schools within different areas of vulnerability, relating this distribution to the results of their performance measured by "aggregate value". The methodology used was with 1) a description of the variables related to characteristics around the schools, 2) the intersection of performance and features found in these schools. The results revealed that there not is a regular evidence relation between the spatial layout of the schools and their performance.

Keywords: social vulnerability; school quality; spatial segregation; neighborbood effect.

\section{Escuelas municipales de Campinas y la vulnerabilidad sociodemográfica: primeras aproximaciones}

Este trabajo discute la distribución de escuelas municipales de Campinas, São Paulo - Brasil, según su localización espacial y desempeño escolar, a partir de los datos de las pesquisas: GERES 2005 - LOED / FE / UNICAMP <http://www.geres. ufmg.br/> y Vulnerabilidad - NEPO / UNICAMP < http://www.nepo.unicamp. br/vulnerabilidade/>. Utilizando referenciales teóricos que sustentan los conceptos de Vulnerabilidad Social, Segregación Espacial, Efecto Hogar y Efecto Escuela, analizamos la distribución de las escuelas dentro de las diferentes zonas de vulnerabilidad, relacionando esa distribución a los resultados de su desempeño medido por el "valor añadido". La metodología utilizada se dio en dos ejes: 1) la descripción de las variables relacionadas a las caracteristicas del entorno de las escuelas; 2) el cruce de las características encontradas y el desempeño de esas escuelas. Los resultados revelaron que no hay una recurrencia clara en relación a la disposición espacial de las escuelas relacionadas a su desempeño.

Palabras clave: vulnerabilidad social; eficacia escolar; segregación espacial; efecto hogar.

\section{VITOR HENRIQUE PARO}

\section{Progressão Continuada, Supervisão Escolar e Avaliação Externa: implicações para a qualidade do ensino}

Derivado de estudo mais amplo sobre a estrutura da escola, este artigo discute resultados de pesquisa de cunho qualitativo realizada em escola pública fundamental sobre questões relacionadas à progressão continuada, à supervisão escolar e à avaliação externa. Tendo presente seu relacionamento com a qualidade do ensino e com a avaliação escolar, esses temas são tratados a partir de um conceito de educação como prática democrática, procedendo-se à crítica da prática pedagógica tradicional. Os dados e análises sugerem que, quanto à progressão continuada, se enfatize a efetividade do ensino, em lugar da passagem 